Federal Reserve Bank of Minneapolis

Research Department Staff Report 478

December 2012

\title{
Engineering a Paradox of Thrift Recession*
}

\author{
Zhen Huo \\ University of Minnesota \\ and Federal Reserve Bank of Minneapolis \\ José-Víctor Ríos-Rull \\ University of Minnesota, \\ Federal Reserve Bank of Minneapolis, \\ CAERP, CEPR, and NBER
}

\begin{abstract}
We build a variation of the neoclassical growth model in which financial shocks to households or wealth shocks (in the sense of wealth destruction) generate recessions. Two standard ingredients that are necessary are (1) the existence of adjustment costs that make the expansion of the tradable goods sector difficult and (2) the existence of some frictions in the labor market that prevent enormous reductions in real wages (Nash bargaining in Mortensen-Pissarides labor markets is enough). We pose a new ingredient that greatly magnifies the recession: a reduction in consumption expenditures reduces measured productivity, while technology is unchanged due to reduced utilization of production capacity. Our model provides a novel, quantitative theory of the current recessions in southern Europe.
\end{abstract}

Keywords: Great Recession, Paradox of thrift, Endogenous productivity JEL Classification: E20, E32, F44

*Ríos-Rull thanks the National Science Foundation for Grant SES-1156228. We are thankful for discussions with Yan Bai, Kjetil Storesletten, and Nir Jaimovich and the comments of Joan Gieseke and of the attendants at the many seminars where this paper was presented. The views expressed herein are those of the authors and not necessarily those of the Federal Reserve Bank of Minneapolis or the Federal Reserve System. 


\section{Introduction}

We develop a model in which recessions are triggered by the desire of households to save more (i.e., because of insufficient demand), and we map our model to a standard modern economy. Our model has three ingredients that provide a very mild departure from standard neoclassical growth theory: (1) It is difficult to reallocate resources from nontradable to tradable production (there are adjustment costs). (2) The labor market is not competitive, although the departure from Walrasian markets in our baseline economy is to pose labor markets as being subject to search frictions à la Mortensen-Pissarides with Nash bargaining as the wage determination mechanism. (3) Goods markets for nontradables require active search from households extending Bai, Ríos-Rull, and Storesletten (2011) to an environment in which reductions in consumption generate reductions in productivity. This happens because households reduce the number of varieties they consume and with this reduction the capacity utilization rate of the economy. We show how, contrary to standard growth models, the desire to save translates to a recession and not to a boom. Although the only two ingredients that are necessary for this to happen are the difficulties in reallocating factors to nontradables and the lack of perfectly flexible labor markets, the novel mechanism that we model here, that households choose both the number of varieties and the quantity of each variety that they consume, is very large quantitatively, reducing by 2.5 times the size of the shocks needed for a given size of output contraction. While our model economy does not include price rigidities, we document the extent to which such rigidities make recessions easier to obtain (smaller shocks).

We also provide a version of our model where instead of shocks to patience, it is shocks to financial costs to provide insurance for the unemployed what generates increases in savings, yet we do not need to abandon the representative agent structure. In this economy financial shocks to the ability of households to smooth consumption generates recessions.

For an increased desire to save to generate a recession, several difficulties have to be present. In particular, saving for the future via either investment or exports must be difficult. In our economy there are adjustment costs that prevent a rapid reallocation of production from consumption to investment or exporting goods. This is in line with several other papers (e.g., Kehoe and Ruhl (2009)) which show that without the labor adjustment there is too much shifting of resources into the tradable sector. In a similar fashion, Midrigan and Philippon (2011) assume that labor is not perfectly substitutable among different sectors, again to avoid a large shift of employment across sectors that would prevent the onset of a recession. Mendoza (2001), Farhi and Werning 
(2012), and Schmitt-Grohe and Uribe (2011) pose the extreme assumption that tradable goods are given exogenously. All of these ingredients have a similar effect of preventing the economy from reallocating resources too quickly.

When a household wants to save more either because it is poorer than before or because its preferences have shifted toward the future, it also wants to work harder. The typical strategy to avoid this response is to prevent the labor market from clearing via some form of wage stickiness, so that labor demand will determine employment (Schmitt-Grohe and Uribe (2011), Midrigan and Philippon (2011), and Farhi and Werning (2012)). We break down the static first-order condition of the household by posing standard labor market search frictions à la Mortensen-Pissarides. Clearly, wage rigidity makes recessions more likely, as we document below, but even the mild deviation from competitive labor markets implied by the search friction is sufficient to generate recessions. Rendahl (2012) also considers a demand-driven economy with search frictions in the labor market. In his economy a transitory negative shock can generate a relatively persistent recession via the slow adjustment of the unemployment rate.

We provide a technical contribution, an extension to Bai, Ríos-Rull, and Storesletten (2011), which modeled goods markets as having frictions where more intense search on the part of the households translates into productivity gains as the economy operates at a higher capacity without more intense use of productive inputs. In that paper, search effort essentially behaved as a substitute to labor, and hence a desire to work harder or save more would have implied more search and an increased productivity, hardly the trademark of recessions. In this paper, we provide a form of search frictions that operate at the level of varieties. Preferences have a taste for variety à la Dixit-Stiglitz, but each variety must be found, which requires search. In our model when consumers want to increase their consumption, they do so by increasing the number of varieties and by consuming more of each variety, and hence search effort is not a substitute for resources but a complement to them. In this manner, the desire to save reduces productivity. In the extended version of the model that accommodates financial frictions, the employed and unemployed members of the household consume different amounts but also search for different number of varieties. In this version, the search friction generates two different properties. First, high-consumption households consume more varieties, which in general requires more search. Second, the market splits locations into those that cater to the rich, which requires little search, and those that cater to the poor, where there is more search (and under some interpretations a cheaper price). In this context, the unemployed substitute their own search for resources, as do the retirees in Aguiar and Hurst (2005) and Aguiar and Hurst (2007). 
A large and growing literature studies recessions generated by a disturbance to the discount factor (or natural rate). Recent key references include Eggertsson (2011), Christiano, Eichenbaum, and Rebelo (2011), Correia, Farhi, Nicolini, and Teles (2011), Rendahl (2012), Eggertsson and Krugman (2012), and Schmitt-Grohe and Uribe (2012). Although our paper shares the same view with this literature that a recession is the result of insufficient demand, it does not hinge on the economy being stacked at the zero lower bound on the nominal interest rate nor on the existence of rigid prices or wages. In fact, in our model, even with flexible prices and wages, shocks to the discount factor still have sizable real effects.

The evidence provided by Mian and Sufi (2010) and Mian and Sufi (2012) using county-level data to show that households' demand is crucial in explaining aggregate economic performance, and that it is also closely linked with households' financial conditions, provides a rationale for looking for financial shocks to households as a source of recessions. In this context, Guerrieri and Lorenzoni (2011) consider a shock to households' borrowing capacity in an Aiyagari-type model and show that it causes a decline in output. However, it does so by reducing the work effort of the best-performing agents, hardly what characterizes the current great recession. Furthermore, the financial shock, if combined with nominal rigidities, can potentially push the economy into a liquidity trap. Eggertsson and Krugman (2012) also study the effect of an exogenous reduction of debt limit and highlight a Fisher-deflation mechanism. Midrigan and Philippon (2011) focus on the home-equity borrowing issue and show that a drop in the leverage ratio reduces the liquidity of households and correspondingly their demand.

This paper is also related to the literature on sudden stops and business cycles in a small open economy. Most of the literature focuses on shocks that affect the production side directly, such as shocks to total factor productivity, investment technology, interest rate premium, terms of trade, or firms' collateral constraints. We do not consider any of those shocks; instead, we consider shocks to the households' desire to spend, which endogenously change measured total factor productivity. In an interesting paper by Mendoza and Yue (2012), imported intermediate goods enter the production function and a reduction of imports leads to an endogenous decline in total factor productivity. Our approach is quite different, as we want to capture the idea that it is the internal demand of households that changes the production frontier.

Section 2 shows how our new mechanism works in a simple version of the model. The model that can be used for quantitative analysis is described in Section 3. Calibration is in Section 4, and the main analysis is in Section 5. Section 6 shows that both adjustment costs and frictions in the labor market are necessary for versions of the growth model with flexible prices to have recessions 
generated by increases in savings due to shocks in patience. Section 7 describes the very large quantitative importance of the (new) mechanism that we develop in this paper. Section 8 poses and uses a model in which the shocks that trigger the increased desire to save are not shocks to patience but rather financial shocks without the need to leave the representative agent abstraction. Throughout our analysis, all versions of the economy have been recalibrated. Section 9 describes what happens when the baseline economy becomes suddenly poorer, and Section 10 analyzes the robustness of our findings to model assumptions. Section 11 concludes. Various appendices describe technical details and additional tables of interest.

\section{A Simple Version of the Model}

To see how the gist of the model works, consider a simple two-period version of our model. Households care about two sets of goods in the first period, which we call tradables and nontradables, and about the amount of tradable goods saved for the second period. Nontradables come in different varieties that have to be found, and households get disutility when they search for those varieties. Nontradable consumption varieties provide utility via a Dixit-Stiglitz aggregator, $\left(\int_{0}^{\mathrm{I}_{N}} c_{N i}^{\frac{1}{\rho}} d_{i}\right)^{\rho}$. Under equal consumption of each variety, this aggregate collapses to $c_{N} \mathrm{I}_{N}^{\rho}$. Finally, we can write the utility function of the household as $u\left(c_{T}, \mathrm{I}_{N}^{\rho} c_{N}, d\right)+\beta v\left(b^{\prime}\right)$, where $d$ is search effort and the second period terms have the standard interpretation of a discount rate and an indirect utility function of savings $b^{\prime}$.

There is a continuum of measure one of varieties. The household chooses how many of those varieties to consume $\mathrm{I}_{N}<1$ by means of exerting sufficient search effort, $d$, to overcome a matching friction. Denote by $\Psi^{d}\left(Q^{g}\right)$ the probability that a unit of search effort finds a variety, where $Q^{g}$ is market tightness in the goods market. The utility of the household is given by $u\left(c_{T}, I^{\rho} c_{N}, d\right)$. We can write the household problem as

$$
\begin{array}{ll}
\max _{\left\{c_{i}\right\}, \mathrm{I}_{N}, c_{T}, d, b^{\prime}} & u\left[c_{T}, \mathrm{I}_{N}^{\rho} c_{N}, d\right]+\beta v\left(b^{\prime}\right) \\
& c_{T}+\mathrm{I}_{N} c_{N} p+b^{\prime}=\pi_{N}+\pi_{T}, \\
& \mathrm{I}_{N}=d \Psi^{d}\left(Q^{g}\right),
\end{array}
$$

where $\pi_{N}+\pi_{T}$ are total resources available measured in units of the tradable good, which come from the profits of the firms. The solution of this problem yields demand functions that, using aggregate 
notation (capital letters to denote aggregate quantities), are $C_{T}\left(p, Q^{g}, \pi ; \beta\right), C_{N}\left(p, Q^{g}, \pi ; \beta\right)$, $\mathrm{I}\left(p, Q^{g}, \pi ; \beta\right), B^{\prime}\left(p, Q^{g}, \pi ; \beta\right)$, and $D\left(p, Q^{g}, \pi ; \beta\right)$, where we are explicitly posing the dependence on the price of nontradables, on market tightness, and on profits, as well as on the households' discount rate that we can treat as a source of shocks.

Matching in the nontradable goods markets works like this. Firms and consumers are matched according to matching function $M^{g}(D, T)$, where $D$ is the aggregate search effort of households and $T$ is the measure of firms in the economy. There is a continuum of measure one of firms, and each one of those firms has a measure one of locations. The probability that a location finds a household is $\Psi^{f}\left(Q^{g}\right)=\Psi^{f}\left(\frac{1}{D}\right)=M^{g}(D, 1)$, while the probability that a search unit, or shopper, finds a variety is $\Psi^{d}\left(Q^{g}\right)=\Psi^{d}\left(\frac{1}{D}\right)=\frac{M^{g}(D, 1)}{D}$. In equilibrium $\Psi^{f}\left(Q^{g}\right)=I_{N}$.

The equilibrium conditions are simple given that production is predetermined, and it involves

$$
\begin{aligned}
Q^{g} & =\frac{1}{D\left(p, Q^{g}, \pi ; \beta\right)}, \\
F^{T} & =C_{T}\left(p, Q^{g}, \pi ; \beta\right)+B^{\prime}\left(p, Q^{g}, \pi ; \beta\right) \\
F^{N} & =C_{N}\left(p, Q^{g}, \pi ; \beta\right), \quad \text { or } \quad \pi_{N}=p F^{N} \Psi^{f}\left(\frac{1}{D}\right) .
\end{aligned}
$$

The first condition states that market tightness is the result of household search; the second, that tradable output is either consumed or saved; and the third, that the amount of nontradable consumption of every variety is that available at each location. Walras' law allows us to choose between the last two equations, since one is market clearing and the other comes from the budget constraint.

To see what is special in this economy, note that in standard models, $Q^{g}=1$, and prices and profits adjust to clear the market. Preferences of households determine savings. If both types of consumption are complements, when households want to save more, say, because of bigger $\beta$, this would be implemented via a decrease in the price of the nontradable good that maintains market clearing (as shown in Figure 1, from point A to point B). In our economy, this is not the case when search is a substitute for consumption (say, because of GHH-type preferences (Greenwood, Hercowitz, and Huffman (1988))). The increased desire to save clearly reduces tradable consumption and, because of complementarity, nontradables are also reduced. With the preferences that we pose, households want to reduce nontradable consumption by reducing the number of varieties as well as the amount consumed of each variety. In this simple economy, the amount consumed 
Figure 1

A Simple Endowment Economy

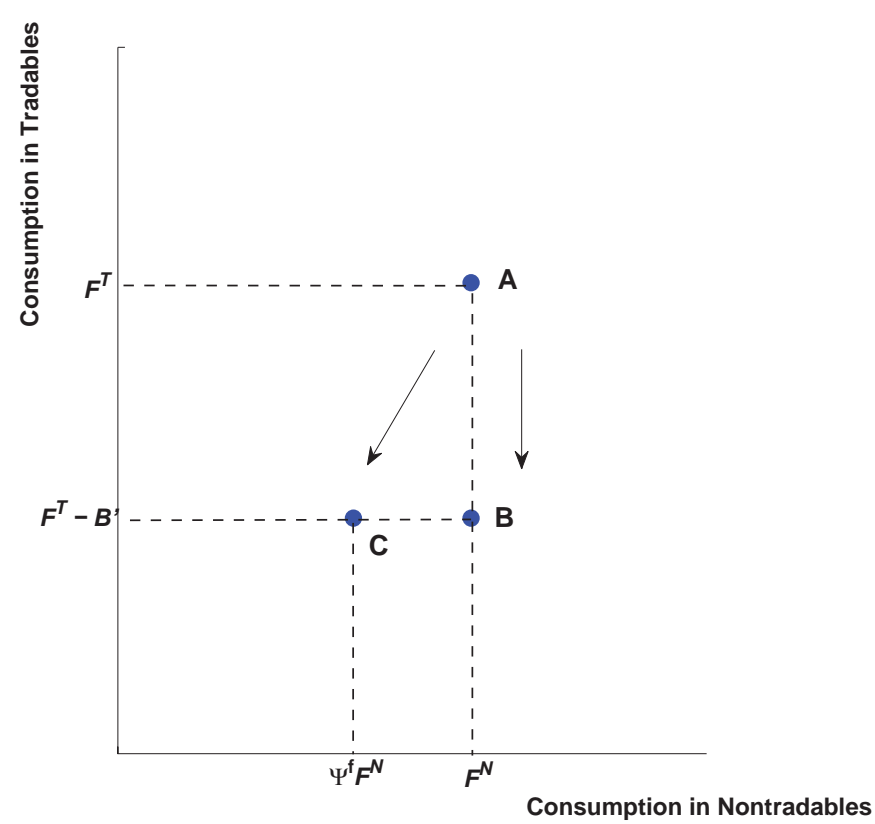

of each variety is predetermined so it cannot drop, but the number of varieties does drop, and with it output, as the economy is now operating at lower capacity, which corresponds to point $C$ in Figure 1. ${ }^{1}$ In this example, profits go down. If this mechanism were persistent, future profits would also go down which is why the paradox of thrift may show up.

This simplified version of our economy illustrates how an increased desire to save can generate a reduction in output via a reduction in measured TFP without either technology or the measured inputs changing. It is the search efforts of households that go down. We next build these ideas into a growth model suitable for quantitative analysis, with dynamic determination of inputs of production.

\footnotetext{
${ }^{1}$ The amount of reduction in tradable consumption depends on the details of preferences, which may not be the same in the two cases (i.e., with and without goods market frictions). What we want to emphasize here is that the consumption of nontradable goods can be lower when the goods market frictions are present.
} 


\section{The Baseline Economy}

Our baseline economy poses a small open economy with the interest rate set by the rest of the world. ${ }^{2}$ There is a representative household or family with many individual agents, all of whom can work. The household fully insures all its members.

\subsection{Goods}

There are two types of goods: tradables, which can be imported and exported and can be used for consumption and investment, and nontradables, which can be used only for local consumption. Nontradables are subject to additional frictions that we now describe in detail.

There is a measure one of varieties of nontradables $i \in[0,1]$, and each one is produced by a monopoly that posts prices and has to deliver the amount of goods demanded at that price. Each one of these firms or varieties itself has a measure one continuum of locations, each with its own capital and labor and a standard constant returns to scale (CRS) technology, $F^{N}(k, n)$.

Each period, consumers have to search and find varieties, and they value both the number of varieties and the quantity consumed of each variety. To obtain varieties, consumers need to search for them, incurring a shopping disutility while doing so. Shoppers that find a variety are randomly allocated to one and only one of its locations. Denote the aggregate measure of shoppers or shopping effort as $D$. The total number of matches between shoppers and firms is determined by a CRS matching function $M^{g}(D, 1)$. Denoting market tightness in the goods market by $Q^{g}=\frac{1}{D}$, the probability that a shopper finds a location becomes

$$
\Psi^{d}\left(Q^{g}\right)=\frac{M^{g}(D, 1)}{D}
$$

while the probability that a location in each firm finds a shopper is equal to the measure of locations of each variety that is filled and is given by

$$
\Psi^{f}\left(Q^{g}\right)=\frac{M^{g}(D, 1)}{1}
$$

Firms in the tradable goods sector operate in a standard competitive market, and we use tradables

\footnotetext{
${ }^{2}$ In what follows, some repetition may occur with respect to the previous section to ensure that this section is self-contained.
} 
as the numeraire. Let the aggregate production function of tradables be given by $F^{T}(k, n){ }^{3}$

\subsection{Labor Market}

Work is indivisible, and all workers are either employed or unemployed. The labor market has a search friction à la Mortensen and Pissarides: firms have to post vacancies and those vacancies, and the unemployed workers are matched via a neoclassical matching function. There is a single labor market where all firms post vacancies, $V_{N}$ by nontradable producers and $V_{T}$ by tradable producers. The number of new matches is given by a CRS matching function $M^{e}(U, V)$, where $U$ is the unemployment rate and $V=V_{N}+V_{T}$ is the total number of vacancies. The probability of finding a job for the unemployed is

$$
\Phi^{w}\left(Q^{e}\right)=\frac{M^{e}(U, V)}{U}
$$

The probability of a vacancy being filled is

$$
\Phi^{f}\left(Q^{e}\right)=\frac{M^{e}(U, V)}{V}
$$

where $Q^{e}=\frac{V}{U}$ is labor market tightness. An employed worker faces a constant probability $\lambda$ of job loss. Wage determination will be discussed in Section 3.8.

\subsection{Households and Preferences}

There is a representative household, or a family with many members, with preferences over a consumption aggregate $c_{A}$, shopping effort $d$, and the fraction of its members that work $n$. The aggregate consumption basket is valued via an Armington aggregator of tradables and nontradables, while nontradables themselves aggregate via a Dixit-Stiglitz formulation with a variable upper bound, yielding

$$
c_{A}=\left(\omega\left[\int_{0}^{\mathrm{I}_{N}} c_{N, i}^{\frac{1}{\rho}} d i\right]^{\frac{\rho(\eta-1)}{\eta}}+(1-\omega) c_{T}^{\frac{\eta-1}{\eta}}\right)^{\frac{\eta}{\eta-1}}
$$

where $c_{N, i}$ is the amount of nontradable good of variety $i, \mathrm{I}_{N} \in[0,1]$ is the measure of varieties of nontradable goods that the household has acquired, $\rho>1$ determines the substitutability among nontradable goods, and $\eta$ controls the substitutability between nontradables and tradables. The

\footnotetext{
${ }^{3}$ Accommodating decreasing returns to scale is trivial with the aid of a fixed factor.
} 
period utility function is given by $u\left(c_{A}, d, n\right)$. Even though the search and matching features imply that workers are rationed, the disutility of working matters for wage determination. Households discount the future at rate $\beta$ and are expected utility maximizers.

\subsection{Asset Markets}

We assume that households own the firms inside their own country that yield dividends $\pi_{N}+$ $\pi_{T}$. Households also have access to (noncontingent) borrowing and lending from abroad at an internationally determined interest rate $r$. Denote the asset foreign position by $b$. Households also receive labor income.

The state variables for the household, in addition to the aggregate state $S$ to be specified later, is the pair $(b, n)$, its assets and the fraction of their members with a job. Households take as given the prices of each variety of nontradables $p_{i}$, the wage $w$, the probability of finding a variety $\Psi^{d}$, the probability of finding a job $\Phi^{w}$, and the firms' dividends, all of which are equilibrium functions of the state.

\subsection{Household's Problem}

Denoting by $S$ the aggregate state vector, we can write the recursive problem of the household in the following manner:

$$
V(S, b, n)=\max _{c_{N, i}, c_{T}, \mathrm{I}_{N}, d} u\left(c_{A}, d, n\right)+\beta \mathbb{E}\left\{V\left(S^{\prime}, b^{\prime}, n^{\prime}\right) \mid \theta\right\}
$$

subject to the definition of the consumption aggregate (11) and

$$
\begin{aligned}
\int_{0}^{\mathrm{I}_{N}} p_{i}(S) c_{N, i} d i+c_{T}+b^{\prime} & =(1+r) b+w(S) n+\pi_{N}(S)+\pi_{T}(S), \\
\mathrm{I}_{N} & =d \Psi^{d}\left[Q^{g}(S)\right], \\
n^{\prime} & =(1-\lambda) n+\Phi^{w}\left[Q^{e}(S)\right](1-n), \\
S^{\prime} & =G(S) .
\end{aligned}
$$

Equation (13) is the household's budget constraint. Equation (14) is the requirement that varieties have to be found, which requires effort $d$ and depends on the goods market tightness. Equation (15) describes the evolution of the household's employment, while (16) is the rational expectations requirement. 
As is standard in economies with varieties, we define aggregates of nontradable consumption bundles and prices:

$$
\begin{aligned}
c_{N} & =\left[\frac{1}{\mathrm{I}_{N}} \int_{0}^{\mathrm{I}_{N}} c_{N, i}^{\frac{1}{\rho}} d i\right]^{\rho}, \\
p & =\left[\frac{1}{\mathrm{I}_{N}} \int_{0}^{\mathrm{I}_{N}} p_{i}^{\frac{1}{1-\rho}} d i\right]^{1-\rho} .
\end{aligned}
$$

Note that $p$ is not a function of $I_{N}$. We can derive the demand schedule for the goods from a particular variety (or firm) $i$, given $c_{N}$ and $p$,

$$
c_{N, i}=\left(\frac{p_{i}}{p}\right)^{\frac{\rho}{1-\rho}} c_{N} .
$$

We can rewrite the consumption aggregate (11) and the budget constraint (14) as ${ }^{4}$

$$
\begin{aligned}
c_{A} & =\left[\omega\left(c_{N} \mathrm{I}_{N}^{\rho}\right)^{-\eta}+(1-\omega) c_{T}^{-\eta}\right]^{-\frac{1}{\eta}} \\
p(S) c_{N} \mathrm{I}_{N}+c_{T}+b^{\prime} & =(1+r) b+w(S) n+\pi_{N}(S)+\pi_{T}(S) .
\end{aligned}
$$

The first order conditions are

$$
\begin{aligned}
& u_{c_{N}}=p(S) \mathrm{I}_{N} u_{c_{T}}, \\
& u_{\mathrm{I}_{N}}=p(S) c_{N} u_{c_{T}}-\frac{u_{d}}{\Psi^{d}\left[Q^{g}(S)\right]}, \\
& u_{c_{T}}=(1+r) \mathbb{E}\left\{\beta u_{c_{T}}^{\prime} \mid \theta\right\} .
\end{aligned}
$$

Equation (22) shows the optimality condition between nontradable and tradable goods. Equation (23) determines the trade-off between the number of varieties and the quantity consumed of each variety: since $\rho>1$, increasing $I_{N}$ is more efficient than increasing $c_{N}$, but searching for different firms is costly. An implication of this equation is that in general, increases in consumption imply an increase of both the amount consumed of each variety and the number of varieties. Equation (24) is the standard Euler equation.

\footnotetext{
${ }^{4}$ See Appendix A for a more detailed derivation.
} 


\subsection{Firms in the Nontradable Goods Sector}

The firm posts prices in each location, and if a shopper shows up, it chooses how much of the good it wants to buy according to the demand schedule derived above. We rewrite this demand schedule as an aggregate function that depends explicitly on both the aggregate state and goods prices: ${ }^{5}$

$$
C\left(p_{i}, S\right)=\left(\frac{p_{i}}{p(S)}\right)^{\frac{\rho}{1-\rho}} C_{N}(S)
$$

To produce the goods, firms have a CRS production function that uses capital $k$ and labor $n$. Recall that there is also a search friction in the labor market, so firms need to post vacancies at cost $\kappa$ per unit in order to increase their labor the following period. Both investment and vacancies use the tradable goods. Given these assumptions, the individual firm's state is $(k, n)$, while the problem that it solves is

$$
\Omega^{N}(S, k, n)=\max _{p_{i}, i, v} \Psi^{f}\left[Q^{g}(S)\right] p_{i} C\left(p_{i}, S\right)-w(S) n-i-v \kappa+\mathbb{E}\left\{\frac{\Omega^{N}\left(S^{\prime}, k^{\prime}, n^{\prime}\right)}{1+r} \mid \theta\right\},
$$

subject to

$$
\begin{aligned}
C\left(p_{i}^{c}, S\right) & \leq F^{N}(k, n), \\
k^{\prime} & =(1-\delta) k+i-\phi^{N}(k, i), \\
n^{\prime} & =(1-\lambda) n+\Phi^{f}\left[Q^{e}(S)\right] v, \\
S^{\prime} & =G(S),
\end{aligned}
$$

where $\phi^{N}(k, i)$ is a capital adjustment cost, which slows down the adaptation of firms to new conditions. Note that both capital and employment are predetermined, and therefore firms have to set the price such that demand does not exceed output. The first order conditions are

$$
\begin{aligned}
\frac{(1+r)}{1-\phi_{i}^{N}} & =\mathbb{E}\left\{\Psi^{f}\left[Q^{g}\left(S^{\prime}\right)\right] p_{i}^{\prime}\left(F_{k}^{N}\right)^{\prime} \frac{1}{\rho}+\frac{1-\delta-\left(\phi_{k}^{N}\right)^{\prime}}{1-\left(\phi_{i}^{N}\right)^{\prime}} \mid \theta\right\}, \\
\frac{\kappa}{\Phi^{f}\left[Q^{e}(S)\right]} & =\frac{1}{1+r} \mathbb{E}\left\{\Psi^{f}\left[Q^{g}\left(S^{\prime}\right)\right]\left(p_{i}^{c}\right)^{\prime}\left(F_{n}^{N}\right)^{\prime} \frac{1}{\rho}-w\left(S^{\prime}\right)-\frac{(1-\lambda) \kappa}{\Phi^{f}\left[Q^{e}\left(S^{\prime}\right)\right]} \mid \theta\right\} .
\end{aligned}
$$

Equations (31) and (32) equate the marginal benefits and marginal costs of increasing investment and vacancies. Clearly, all firms choose the same price in equilibrium, that is, $p_{i}=p(S)$ for all

\footnotetext{
${ }^{5}$ Since we assume random search in the goods market, we will ignore the issues of rationing in each location.
} 
$i \in[0,1]$. We denote the solution of this problem by the subindex $N$ to indicate that they refer to nontradables.

\subsection{Firms in the Tradable Goods Sector}

Unlike the nontradable goods sector, firms in the tradable goods sector operate in a frictionless, perfectly competitive environment. To accommodate the possibility of decreasing returns to scale, we pose that in addition to capital and labor, firms also need to use another factor, land, available in fixed supply, as an input of production. Without loss of generality, we assume that there is a firm that operates each unit of land. There are also adjustment costs to expand capital and employment, given by functions $\phi^{T, k}(k, i)$ and $\phi^{T, n}\left(n^{\prime}, n\right)$, which makes it difficult for this sector to expand quickly. The problem of the firms in the tradable goods sector is

$$
\begin{aligned}
& \Omega^{T}(S, k, n)=\max _{i, v} F^{T}(k, n)-w(S) n-i-v \kappa-\phi^{T, n}\left(n^{\prime}, n\right)+\mathbb{E}\left\{\frac{\Omega^{T}\left(S^{\prime}, k^{\prime}, n^{\prime}\right)}{1+r} \mid \theta\right\}, \\
& \qquad \begin{aligned}
k^{\prime} & =(1-\delta) k+i-\phi^{T, k}(k, i), \\
& n^{\prime}=(1-\lambda) n+\Phi^{f}\left[Q^{e}(S)\right] v, \\
& S^{\prime}=G(S) .
\end{aligned}
\end{aligned}
$$

The first order conditions are

$$
\begin{gathered}
\frac{1+r}{1-\phi_{i}^{T, k}}=\mathbb{E}\left\{\left(F_{k}^{T}\right)^{\prime}+\frac{1-\delta-\left(\phi_{k}^{T, k}\right)^{\prime}}{1-\left(\phi_{i}^{T, k}\right)^{\prime}} \mid \theta\right\}, \\
\frac{\kappa}{\Phi^{f}\left[Q^{e}(S)\right]}+\phi_{n^{\prime}}^{T, n}=\frac{\mathbb{E}\left\{\left(F_{n}^{T}\right)^{\prime}-w\left(S^{\prime}\right)-\left(\phi_{n}^{T, n}\right)^{\prime}+(1-\lambda)\left(\frac{\kappa}{\Phi^{f}\left[Q^{e}\left(S^{\prime}\right)\right]}+\left(\phi_{n^{\prime}}^{T, n}\right)^{\prime}\right) \mid \theta\right\}}{1+r} .
\end{gathered}
$$

Equation (37) and Equation (38) are similar to the optimality condition for nontradable firms. When necessary, we use the subindex $T$ to refer to tradables.

\subsection{Wage Determination}

The wage rate is determined via Nash bargaining. Unlike in Krusell, Mukoyama, and Şahin (2010) and Nakajima (2012), where agents internalize the effect of additional saving on their bargaining position, here we assume that individual workers and firms take the wage as given and act as 
though a worker-firm pair like themselves bargain over the wage rate. ${ }^{6}$ The value of an additional employed worker for the household with wage $w$ is

$$
\widetilde{V}_{n}(w, S)=w u_{c_{T}}(S)-\varsigma+\beta\left(1-\lambda-\Phi^{w}\left[Q^{e}(S)\right]\right) \mathbb{E}\left\{V_{n}\left(S^{\prime}\right) \mid \theta\right\}
$$

where $V_{n}(S)=\widetilde{V}_{n}(w(S), S)$ and $u_{c_{T}}(S)$ is the marginal utility for the representative household. The value of an additional worker for a firm in the nontradable goods sector with wage $w$ is

$$
\widetilde{\Omega}_{n}^{N}(w, S)=\Psi^{f}\left[Q^{g}(S)\right] p(S) F_{n}^{N}(S) \frac{1}{\rho}-w+\frac{(1-\lambda)}{1+r} \mathbb{E}\left\{\Omega_{n}^{N}\left(S^{\prime}\right) \mid \theta\right\}
$$

and for a firm in the tradable goods sector is

$$
\widetilde{\Omega}_{n}^{T}(w, S)=F_{n}^{T}(S)-w-\phi_{n}^{T, n}(S)+\frac{(1-\lambda)}{1+r} \mathbb{E}\left\{\Omega_{n}^{T}\left(S^{\prime}\right) \mid \theta\right\}
$$

where $\Omega_{n}^{N}(S)=\widetilde{\Omega}_{n}^{N}(w(S), S)$ and $\Omega_{n}^{T}(S)=\widetilde{\Omega}_{n}^{T}(w(S), S)$. Firms may not value workers equally, that is, $\widetilde{\Omega}_{n}^{T}$ may not be the same as $\widetilde{\Omega}_{n}^{N}$. We assume that the wage that is set in the market is the outcome from a bargaining process between a representative worker and a weighted value of the evaluation of the worker by firms, with weights given by the employment share of each sector.

With these elements, the Nash bargaining problem becomes

$$
w(S)=\max _{w}\left[\widetilde{V}_{n}(w, S)\right]^{\varphi}\left[\chi(S) \widetilde{\Omega}_{n}^{N}(w, S)+(1-\chi(S)) \widetilde{\Omega}_{n}^{T}(w, S)\right]^{1-\varphi}
$$

where $\varphi$ is the bargaining power of households and $\chi(S)=\frac{n_{N}}{n_{N}+n_{T}}$ is the employment share of the nontradable goods sector. Taking the derivative with respect to $w$ yields the first order condition

$$
\varphi u_{c_{T}}(S)\left[\chi(S) \widetilde{\Omega}_{n}^{N}(w, S)+(1-\chi(S)) \widetilde{\Omega}_{n}^{T}(w, S)\right]=(1-\varphi) \widetilde{V}_{n}(w, S)
$$

In steady state, the wage rate is given by

$$
w=\varphi\left[\chi\left(\Psi^{f}\left(Q^{g}\right) p F_{n}^{N} \frac{1}{\rho}\right)+(1-\chi) F_{n}^{T}+Q^{e} \kappa\right]+(1-\varphi) \frac{\varsigma}{u_{c_{T}}} .
$$

\footnotetext{
${ }^{6}$ If instead, for example, we allow an individual household to bargain directly with firms for their workers, the household will have an incentive to accumulate additional assets to improve their outside option and increase the wage rate when bargaining. However, as shown in both Krusell, Mukoyama, and Şahin (2010) and Nakajima (2012), the effect of additional savings on the wage rate is small when the household's wealth is not close to zero, as is the case with representative households. This issue is also discussed in Choi and Ríos-Rull (2008).
} 
We can think of the wage rate as a weighted average of the marginal product of labor and the savings on vacancy postings on the one hand, and of the worker's forfeited leisure on the other. ${ }^{7}$

We will also explore environments in which wages are set through Nash bargaining, but the workers and firms can only renegotiate contracts with a certain probability. In Section 5.3, we investigate how wage rigidity affects the model's performance.

\subsection{Aggregate State}

The aggregate state of the economy includes the state vector, the production capacity of the economy (capital and labor in each sector), and its net foreign asset position, $S=\left\{\theta, K_{N}, N_{N}, K_{T}, N_{T}, B\right\}$, where $\theta$ is the vector of shocks.

\subsection{Equilibrium}

Equilibrium is a set of decision rules and values for the household: $\left\{c_{N}, c_{T}, d, \mathrm{I}_{N}, b^{\prime}, V\right\}$ as functions of its state $(S, b, n)$, firms' decision rules and values: $\left\{i_{N}, v_{N}, k_{N}^{\prime}, p_{i}, \Omega^{N}\right\}$ as functions of its state $\left(S, k_{N}, n_{N}\right)$ in the nontradable goods sector, firms' decision rules and values: $\left\{i_{T}, v_{T}, k_{T}^{\prime}, \Omega^{T}\right\}$ as functions of its state $\left(S, k_{T}, n_{T}\right)$ in the tradable goods sector, and aggregate variables for nontradable goods $C_{N}$ and tradable goods $C_{T}$, total employment $N$, total vacancies $V$, total shopping effort $D$, labor market tightness $Q^{e}$, goods market tightness $Q^{g}$, total bonds holding $B$, aggregate capital $K_{N}$, employment $N_{N}$, investment $I_{N}$, vacancies $V_{N}$ and profit $\pi_{N}$ in the nontradable goods sector, aggregate capital $K_{T}$, employment $N_{T}$, investment $I_{T}$, vacancies $V_{T}$ and profit $\pi_{T}$ in the tradable goods sector, aggregate price index $p$ and wage rate $w$ as functions of aggregate state $S=\left(\theta, K_{N}, N_{N}, K_{T}, N_{T}, B\right)$, such that

1. Policy and value functions solve the corresponding problems.

2. Individual decisions are consistent with aggregate variables.

3. The wage rate $w$ is determined via the Nash bargaining process (42).

4. Tradables and nontradables markets clear.

\footnotetext{
${ }^{7} \mathrm{~A}$ minor difference from the standard labor search model is that the wage rate has a dynamic component under uncertainty. The reason is that firms discount future profits using the world interest rate $r$ instead of the households' stochastic discount factor.
} 
Note that in equilibrium, $I_{N}=\Psi^{f}\left(Q^{g}\right)$, i.e., consumers' demand directly translates into firms' capacity.

\subsection{Comments}

Note that this economy may have multiple steady states with varying foreign asset positions. ${ }^{8}$ In fact, any unexpected temporary change in any parameter will end up with the economy being in a long-run position different from the one in which it started.

\section{Calibration}

We start by discussing some details of national accounting in Section 4.1, in Section 4.2 we describe the functional forms used and the parameters involved, and we finish in Section 4.3 by setting the targets that the model economy has to satisfy in the steady state.

\subsection{NIPA and Variable Definitions Issues}

Real output is given by

$$
Y=p^{*} \Psi^{f}\left(Q^{g}\right) F^{N}\left(K_{N}, N_{N}\right)+F^{T}\left(K_{T}, N_{T}\right)
$$

where $p^{*}$ is the steady state price of nontradables. This amounts to measuring output using base year prices instead of current prices. Let $Y_{N}=p^{*} \Psi^{f}\left(Q^{g}\right) F^{N}\left(K_{N}, N_{N}\right)$ denote nontradable output and $Y_{T}=F^{T}\left(K_{T}, N_{T}\right)$ denote tradable output. Total consumption is $C=p^{*} I_{N} C_{N}+C_{T}$. Total employment is $N=N_{N}+N_{T}$. Total capital is $K=K_{N}+K_{T}$. Total investment is $I=I_{N}+I_{T}$. Let $v$ denote the labor share in steady state. Total factor productivity or the measured Solow residual, $Z$, is defined a

$$
Z=\frac{Y}{K^{1-v} N^{v}}
$$

\subsection{Functional Forms and Parameters}

Preferences We adopt GHH preferences between consumption and shopping effort, whereas the working disutility enters as an additively separable term (any consideration of Frisch elasticities is irrelevant because the work disutility only matters for wage determination). The period utility

\footnotetext{
${ }^{8} \mathrm{~A}$ stationary recursive equilibria for the stochastic version requires $1+r<\beta^{-1}$ due to precautionary savings. Given the small quantitative nature of these issues, we ignore them in what follows.
} 
function is then given by

$$
u\left(c_{A}, d, n\right)=\frac{1}{1-\sigma}\left(c_{A}-\xi d\right)^{1-\sigma}-\varsigma n
$$

The units for search effort do not matter. We write $\xi$ only because we have a steady-state target for $d$.

With GHH preferences, the number of varieties of nontradable goods $\mathrm{I}_{N}$ acts like a normal good, that is, when consumers want to increase (decrease) the consumption of nontradable goods, they increase (decrease) both the quantity of the good of each variety as well as the total number of varieties, which implies that $\mathrm{I}_{N}$, and hence measured TFP, is procyclical. Other specifications do not have this property (see Appendix B for a more detailed discussion). The preference parameters are then the discount factor $\beta$, the risk aversion parameter of sorts, $\sigma$, the parameter that determines average shopping effort $\xi$, and the working disutility, $\varsigma$. As discussed before, $c_{A}$, the aggregator of consumption, is

$$
c_{A}=\left[\omega\left(c_{N} \mathrm{I}_{N}^{\rho}\right)^{\frac{\eta-1}{\eta}}+(1-\omega) c_{T}^{\frac{\eta-1}{\eta}}\right]^{\frac{\eta}{\eta-1}},
$$

where the parameters are the elasticity of substitution between nontradable and tradable goods, $\eta$, the elasticity of substitution among nontradables, $\rho$, and the nontradable-bias or home-bias parameter, $\omega$.

Technology The production function of nontradables is

$$
F^{N}(k, n)=z_{N} k^{\theta^{N}} n^{1-\theta^{N}}
$$

where $z_{N}$ is a parameter determining units. The production function of tradables is

$$
F^{T}(k, n)=z_{T} k^{\theta_{k}^{T}} n^{\theta_{n}^{T}} L^{1-\theta_{k}^{T}-\theta_{n}^{T}}=z_{T} k^{\theta_{k}^{T}} n^{\theta_{n}^{T}} .
$$

Since the supply of land is limited, $L=1$, the production function has decreasing returns to scale (DRS) in capital and labor.

Adjustment Cost The capital adjustment cost in the nontradable goods sector is given by

$$
\phi^{N}(k, i)=\frac{\epsilon^{N}}{2}\left(\frac{i}{k}-\delta\right)^{2} k
$$


where $\delta$ is the capital depreciation rate and $\epsilon^{N}$ determines the size of the adjustment cost. Similarly, the capital adjustment cost in the tradable goods sector is

$$
\phi^{T, k}(k, i)=\frac{\epsilon^{T, k}}{2}\left(\frac{i}{k}-\delta\right)^{2} k .
$$

In addition to the capital adjustment cost, producing for tradable goods also involves adjustment costs in employment,

$$
\phi^{T, n}\left(n^{\prime}, n\right)=\frac{\epsilon^{T, n}}{2}\left(\frac{n^{\prime}}{n}-1\right)^{2} n .
$$

Nash Bargaining Workers' bargaining power is $\varphi$.

Matching The matching technology in the labor market is

$$
M^{e}(U, V)=\nu^{e} U^{\mu} V^{1-\mu}
$$

and in the nontradable goods market is

$$
M^{g}(D, T)=\nu^{g} D^{\alpha} T^{1-\alpha}
$$

where $\mu$ and $\alpha$ determine the elasticity of the matching probability with respect to market tightness. There is no need to specify units, as those are determined by $\kappa$ and $\xi$.

Wealth This economy has a continuum of steady states differing in the net foreign asset position. We look at the steady state with zero net asset foreign position.

\subsection{Targets and Values}

We choose a period to be six weeks so that the unemployment duration can be short. A first group of 6 parameters can be determined exogenously, i.e., they imply targets that are independent of the equilibrium allocation. Table 1 summarizes the targets and the implied parameter values. We set risk aversion to 2 and the rate of return to $4 \%$ annually. We choose the elasticity of substitution between tradable and nontradable goods, $\eta$, to be 0.83 , the benchmark value used in Bianchi (2011), which is also similar to the one estimated by Heathcote and Perri (2002). We set the elasticity of the job finding rate with respect to labor market tightness, $\mu$, to 0.5 , which lies in 
the middle of existing empirical estimates. ${ }^{9}$ For the bargaining power $\varphi$, Shimer (2005) sets it equal to 0.72 solely on the basis of satisfying the Hosios condition, while Hagedorn and Manovskii (2008) use a much smaller number, 0.05. This parameter is not identified independently from the value of leisure. We choose an intermediate value 0.35 for the baseline calibration, which is in the middle of those two polar cases. The price markup $\rho$ reflects the substitutability among the nontradable goods as well as the price markup the monopolistic firms will set. In the literature, there is no solid evidence on how large this parameter should be. Basu and Fernald (1997), using micro reasoning, claim that the implied markup is not significantly greater than 1 (1.03), while Christiano, Eichenbaum, and Evans (2005) estimate the price markup using macro data and obtain a value ranging from 1.01 to 1.85 . We have set $\rho=1.05$. In the section on the robustness check, we vary $\rho, \mu, \varphi$ and $\eta$.

TABle 1

Exogenously Determined Parameters of the Baseline Economy

\begin{tabular}{lc}
\hline \hline \multicolumn{1}{c}{ Parameter } & Value \\
\hline Risk aversion, $\sigma$ & 2.0 \\
Annual rate of return, $\beta$ & $\frac{1}{\beta^{8}}-1=4 \%$ \\
Labor matching elasticity, $\mu$ & 0.50 \\
Elasticity of substitution bw tradables and nontradables, $\eta$ & 0.83 \\
Workers' bargaining power, $\varphi$ & 0.35 \\
Price markup $\rho$ & 1.05 \\
\hline \hline
\end{tabular}

The second group of parameters is not the direct implication of any single target, but can be determined out of steady-state conditions, which requires the specification of sufficient steady-state moments. There are 13 such parameters: 3 preference parameters, $\{\omega, \xi, \varsigma\}, 6$ production parameters $\left\{z_{N}, z_{T}, \theta_{N}, \theta_{T}^{k}, \theta_{T}^{n}, \delta\right\}, 2$ search friction parameters $\left\{\nu^{e}, \nu^{g}\right\}$, and 2 labor market parameters $\{\lambda, \kappa\}$. Table 2 lists the parameters and associated steady-state conditions. ${ }^{10}$ While many of those parameters in Table 2 have economic meaning, others are just the determinants of units. Accordingly, the table separates these two blocks.

The targets of the job flows are standard: an employment rate of $93 \%$ to accommodate movements

\footnotetext{
${ }^{9}$ Shimer (2005) considers the elasticity to be 0.72, Merz (1995) 0.4, and Hall (2005) 0.24.

${ }^{10}$ The term "associated" refers to the attempt to link targets and moments according to some intuitive link between them. Mathematically, they are all interdependent.
} 
in labor force participation, and a monthly job finding rate of .45. We target a capacity utilization of $81 \%$, which is the average of the official data series (Corrado and Mattey (1997)), and a labor share of $60 \%$ in both the nontradable and tradable goods sector. We target the tradable goods-output ratio to be $30 \%$. Following the literature, the tradable goods sector typically includes agriculture, mining, and manufacturing industries. In southern Europe, the tradable goods sector accounts for about $25 \%$ of total output. Since in our model the nontradable goods sector is subject to the search friction, we therefore classify the construction of both housing and business structures as tradables, which increases the share of the tradable sector to $30 \%$ of total output. We choose a contribution of land to output of tradables to be a size equal to that of capital, which determines the size of the decreasing returns of the sector. We target a vacancy cost to output ratio of 0.0374 . The literature has few direct estimates of the vacancy cost. Silva and Toledo (2009) report the flow vacancy costs to be $4.3 \%$ of the quarterly wage and the training costs to be $55 \%$ of the quarterly wage. We consider the vacancy costs as the sum of all of these recruitment-related costs. Hagedorn and Manovskii (2008) and Shimer (2012) have a smaller vacancy cost because they take only the flow vacancy cost into account. We also target an annual capital-output ratio of 2.75 .

We normalize output, the relative price of nontradables, and market tightness in both labor and goods markets to 1 . The parameters more closely related to these unit targets are the definition of units in the production function $z_{T}$ and $z_{N}$ as well as the cost per vacancy, $\kappa$, and the parameter that transforms search units into utils, $\xi$.

The last group of parameters has no steady-state implications, and we set the parameters according to their dynamic implications. We choose the capital adjustment cost in the nontradable goods sector $\epsilon^{N}$ such that the immediate response of nontradable investment $i_{N}$ is four times as large as the response of nontradable output $Y_{N}$ at its lowest point. That is, we want a $1 \%$ increase (decrease) in nontradable output in our exercises to be associated with a $4 \%$ decrease in investment in nontradables. We want output in the tradable sector to expand by $5 \%$ when total real output $Y$ drops by $1 \%$, and we want adjustments in labor and capital of tradables to be symmetric. A higher $\alpha$ implies a larger volatility of capacity in the goods market, and a larger role played by consumers' demand in shaping TFP. We choose $\alpha$ such that when total output declines by $1 \%$, the employment rate decreases by $0.5 \%$. 
TABLE 2

Steady-State Targets and Associated Parameters of the Baseline Economy

\begin{tabular}{lccc}
\hline \hline Target & Value & Parameter & Value \\
\hline Share of tradables $\frac{F_{T}^{*}}{Y^{*}}$ & 0.3 & $\omega$ & 0.91 \\
Unemployment rate, $U^{*}$ & $7 \%$ & $\lambda$ & 0.05 \\
Monthly job finding rate & $45 \%$ & $\nu^{e}$ & 0.67 \\
Occupancy Rate, $\frac{C_{N}^{*}}{F_{N}^{*}}$ & 0.81 & $\nu^{g}$ & 0.81 \\
Capital to output ratio $\frac{K^{*}}{Y^{*}}$ & 2.75 & $\delta$ & 0.007 \\
Labor Share in nontradables & 0.6 & $\theta_{N}$ & 0.67 \\
Labor Share in tradables & 0.6 & $\theta_{T}^{N}$ & 0.64 \\
Equal Role of Capital and Land in Tradables, & $2 \theta_{T}^{K}+\theta_{T}^{N}=1$ & $\theta_{T}^{K}$ & 0.18 \\
Vacancy Posting to Output Ratio & 0.037 & $\varsigma$ & 0.80 \\
\hline \multicolumn{1}{c}{ Units Parameters } & & \\
\hline Output, $Y^{*}$ & 1 & $z_{N}$ & 0.45 \\
Relative price of nontradables, $p^{*}$ & 1 & $z_{T}$ & 0.52 \\
Market tightness in labor markets, $\frac{U^{*}}{V^{*}}$ & 1 & $\kappa$ & 0.53 \\
Market tightness in goods markets, $D^{*}$ & 1 & $\xi$ & 0.02 \\
\hline
\end{tabular}

TABLE 3

Dynamically Calibrated Parameters of the Baseline Economy

\begin{tabular}{lccc}
\hline \hline Target & Value & Parameter & Value \\
\hline Response of nontradable investment & $\frac{\Delta I^{N}}{\Delta Y^{N}}=4$ & $\epsilon^{N}$ & 21.29 \\
Response of tradable output & $\frac{\Delta Y^{T}}{\Delta Y}=-5$ & $\epsilon^{T, n}$ & 9.84 \\
Symmetry of tradable adjustment costs & $\epsilon^{T, k}=\epsilon^{T, n}$ & $\epsilon^{T, k}$ & 9.84 \\
Response of labor to output & $\frac{\Delta N}{\Delta Y}=.5$ & $\alpha$ & 0.19 \\
\hline \hline
\end{tabular}

\section{A Recession Induced by a Shock to the Discount Factor}

We are now ready to explore the properties of recessions induced by an attempt to save more. We use relatively permanent shocks to the discount factor as a proxy for financial shocks, but in 
Section 8 we extend the model in such a way as to accommodate explicit financial shocks that make consumption smoothing difficult.

A household that suffers a shock to its patience wants to work harder and save more by reducing its consumption of both tradables and nontradables. Its willingness to work more translates to a wage drop, but not in more work unless firms pose more vacancies. Less tradable consumption translates directly into more net exports. Given our assumptions on preferences, households implement a reduction of nontradables by reducing both the number of varieties and the quantity of each variety, which in turn reduces productivity (fewer locations are occupied), and the prices of nontradables and, consequently, the output and profits of nontradables for a few periods. The tradable sector expands due to the reduction in wages, but only in a limited way due to the decreasing returns to scale of this sector and to the adjustment costs that slow down its expansion.

Specifically, consider the following $\operatorname{AR}(1)$ stochastic process: $\log \tau_{t}=\rho^{\tau} \log \tau_{t-1}+\varepsilon_{t}, \quad \varepsilon_{t} \sim$ $\mathrm{N}\left(0, \sigma^{\tau}\right)$, with persistence $\rho^{\tau}=0.95$. Consider now the following version of the utility function:

$$
\mathbb{E}\left\{\sum_{t=0}^{\infty} \tau_{t} \beta^{t} u\left(c_{t}, d_{t}, n_{t}\right)\right\}
$$

Our strategy is to look for an innovation $\varepsilon_{t}$ capable of reducing real output by $1 \%$. Clearly, the lower the required value of $\varepsilon_{t}$, the more vulnerable the economy is to recessions.

We start in Section 5.1 by looking at the baseline model, and in Section 5.2 we look at the properties of an economy with much higher transaction costs. In Section 5.3 we look at the behavior o anf economy with alternative wage determination protocols (staggered wages à la Calvo for one year and a constant labor share).

\subsection{Performance of the Baseline Model}

The first row of Table 4 displays the size and the sign of the innovation of the shock required to produce a drop in output of $1 \%$ as well as the implied change of employment, of the measured Solow residual, and of total consumption. The size of the temporary increase in the discount rate is a little more than $1 \%$. By itself, this statistic does not tell us much, but it is useful for comparisons. Recall that the economy was calibrated to generate a drop in employment of .5\%. We see that there is a reduction in measured TFP of . $72 \%$, while consumption drops by $4.5 \%$. The reduction of nontradable consumption is responsible for the reduction in measured TFP. 
TABLE 4

Statistics for a $1 \%$ Drop in Output Generated

by Shocks to the Discount Factor in Various Economies

\begin{tabular}{|c|c|c|c|c|}
\hline Model economy & Pref Shock & Employment & TFP & Consumption \\
\hline Baseline economy & 1.12 & -0.50 & -0.72 & -4.50 \\
\hline Baseline + high adjustment cost & 1.01 & -0.74 & -0.52 & -3.14 \\
\hline Baseline + staggered wage & 0.55 & -0.85 & -0.47 & -2.72 \\
\hline Baseline + staggered wage + high cost & 0.45 & -1.02 & -0.36 & -2.03 \\
\hline Baseline + constant labor share & 0.69 & -0.76 & -0.51 & -3.06 \\
\hline Baseline with very low adjustment costs & 1.44 & 0.35 & -1.51 & -8.42 \\
\hline Frictionless markets & -0.50 & -1.76 & 0.01 & 4.37 \\
\hline Frictionless labor with goods market friction & -0.62 & -2.25 & 0.25 & 5.22 \\
\hline Baseline without goods market friction & 2.59 & -1.25 & -0.20 & -9.00 \\
\hline Baseline w/o goods market friction and high adj cost & 1.79 & -1.39 & -0.10 & -4.69 \\
\hline Baseline w/o goods market friction and staggered wages & 0.83 & -1.38 & -0.14 & -3.59 \\
\hline Baseline w/o goods market friction and constant labor share & 1.14 & -1.34 & -0.14 & -4.41 \\
\hline
\end{tabular}

Figure 2 displays the impulse response of the main macroeconomic variables to the shock. The panels cover 8 years for the baseline economy, which is depicted in blue. Here are several interesting features of the ensuing recession beyond those that we imposed (the $1 \%$ drop in output and .5\% drop in employment):

1. The Solow residual drop of .72 lingers for a while and does not recover its original value for at least five years.

2. Employment recovers quite fast, within a year.

3. Consumption drops over $4 \%$ and recovers slowly. The drop is much higher for tradables than for nontradables, as the price of the latter drops, quite dramatically indeed, about $18 \%$.

4. There is a large increase in the output of tradables, which is due to an increase in net exports, which jumps to $4 \%$ of GDP, as investment suffers quite a large reduction, almost $10 \%$. 
FIGURE 2

Impulse Responses in the Baseline and High Adjustment Cost Economies

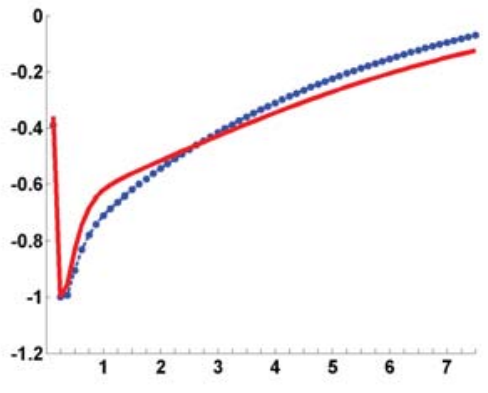

Real output

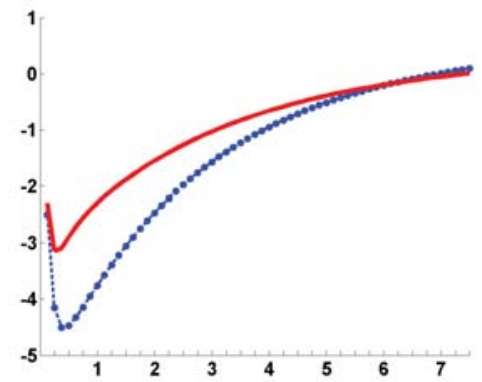

Consumption

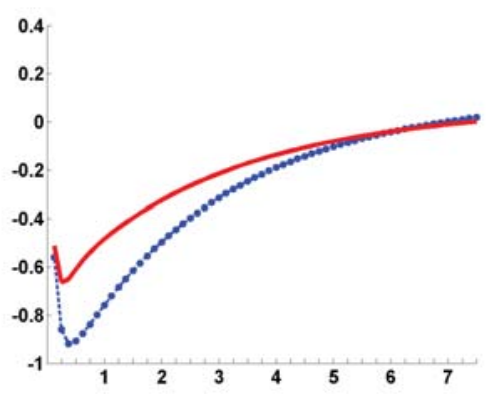

Number of varieties

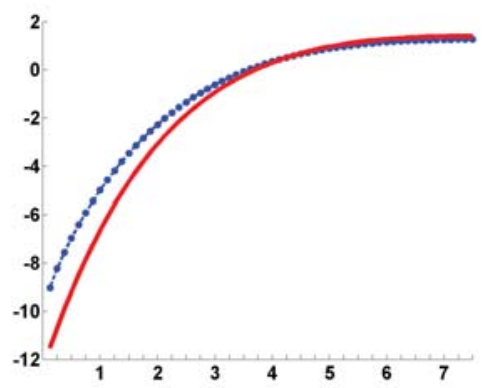

Investment

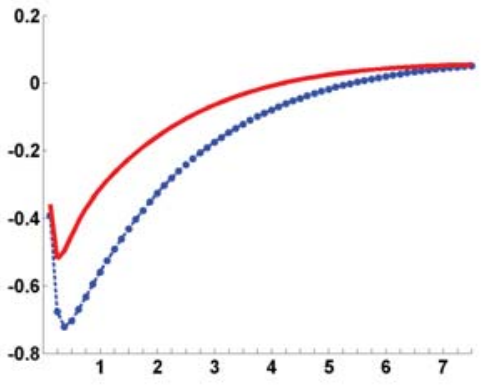

Solow residual

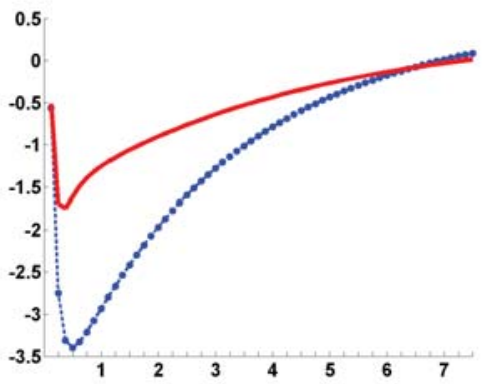

Output of nontradables

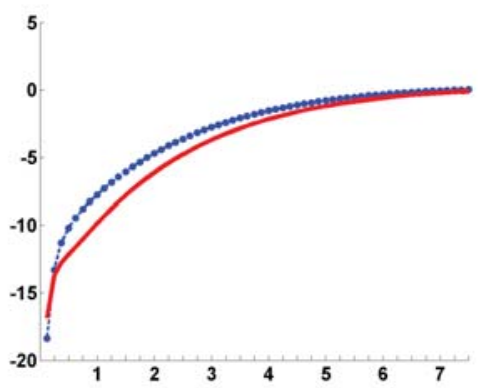

Price for nontradables

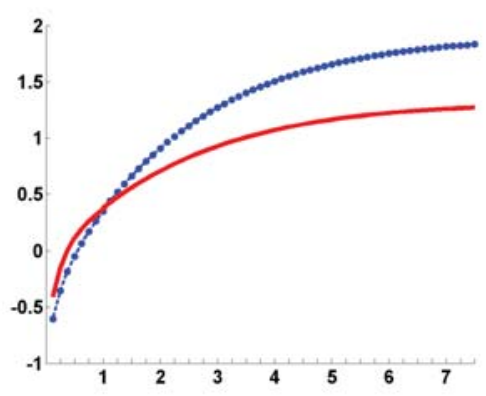

Wealth

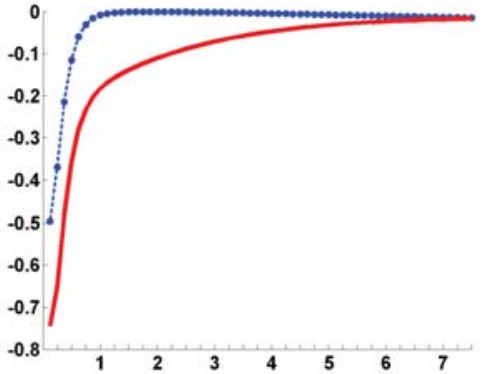

Employment

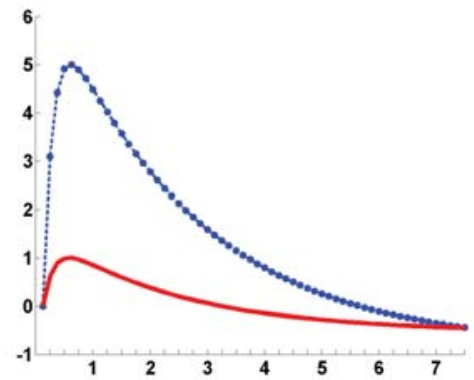

Output of tradables

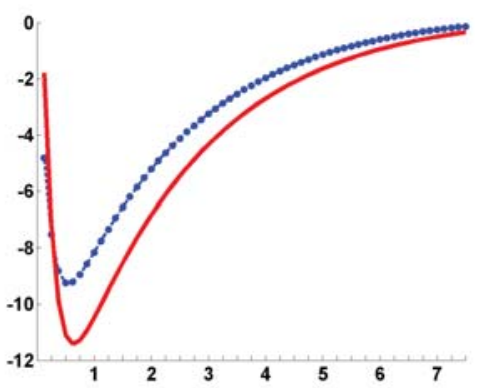

Wage

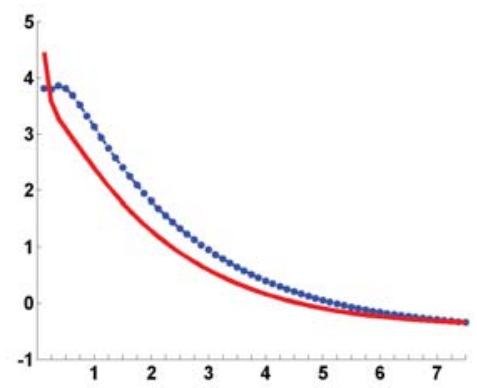

Net export/output ratio

23 
5. The drop in nontradable consumption is due to both the number of varieties and the quantity consumed of each variety, but more of the latter.

6. Wages measured in tradables goods drop quite dramatically. Interestingly, wages keep falling after the initial drop for almost one year. This is due to the high value of the match in the tradables sector due to the adjustment costs. Once the expansion of this sector is almost completed, the bargaining edge of the workers disappears, and wages get to their lowest point.

7. There is a paradox of thrift. Despite the attempt to increase savings, there is a reduction for a few periods in the value of wealth, as measured by the sum of the foreign bonds and the present discounted sum of profits,

$$
W_{t}=(1+r) b_{t}+\sum_{k=t}^{\infty} \frac{\pi_{N, k}+\pi_{T, k}}{(1+r)^{k-t}}
$$

It takes half a year for wealth to recover its initial level. Eventually, wealth increases by $1.6 \%$.

8. There is a massive increase in net exports of almost $4 \%$. In the long run, the economy has a current account deficit due to its long-run positive net foreign asset position.

To summarize, in the baseline economy an increase in savings generates a long-lasting recession with loss of both employment and productivity. The recession is accompanied by an increase in net exports.

To learn more, we explore the properties of recessions in various alternative economies. We start with an economy with high adjustment costs in the tradable goods sector that makes it much more difficult to expand output in that sector (Section 5.2). We then move on to explore various alternative wage determination protocols, a staggered wage à la Calvo, and a constant labor share in Section 5.3.

\subsection{High Adjustment Costs in the Tradable Goods Sector}

This economy and the baseline share the steady state, so we explore the implications of these costs by increasing the adjustment costs for labor and capital in equal magnitude $\left(\epsilon^{T, n}=\epsilon^{T, k}\right)$ to reduce the expansion of the tradable sector to $1 \%$.

The second row of Table 4 shows that the size of the shock needed to generate a $1 \%$ reduction 
in output is about $90 \%$ of that in the baseline economy, but now the drop in employment is larger $(0.74 \%)$ and that of TFP smaller $(0.52 \%)$ due to the lower employment creation in tradables. The red lines in Figure 2 describe the dynamic paths of this economy. There is a smaller (3\%) reduction in consumption and a larger $(12 \%)$ reduction in investment relative to the baseline economy, while the drop in the wage is higher. As in the baseline economy, there is also a paradox of thrift, although the long-term success of the attempt to save is much smaller (the final increase in wealth is about one-half).

Notice that not only is there a larger drop in employment compared with the baseline model, but it also takes longer for employment to recover. In an economy with no adjustment costs, total employment will not decrease at all; instead, there would be an export-based expansion. We take this as evidence that the tradable sector has to have sizable adjustment costs.

\subsection{Alternative Wage Protocols}

We now explore economies with alternative wage setting protocols: staggered wages with an average duration of one year and a labor compensation scheme that keeps the labor share constant. ${ }^{11}$

\subsubsection{Economy with Staggered Wage Contracts}

In the baseline economy, despite the holdup problem implied by Nash bargaining with labor search frictions, there is a large drop in wages. There is an extensive literature (see Hall (2005), for example) documenting that adding wage stickiness can help Mortensen-Pissarides type models to account for employment volatility. In this section, we examine the role of wage stickiness in a Calvo-style wage contracting environment, similar to Gertler and Trigari (2009). We assume that, every period, a fraction $\theta_{w}$ of employed workers have the chance to renegotiate their wages with firms. Denote the economy-wide average wage rate by $w(S)$ and the newly negotiated wage rate by $\widetilde{w}(S)$. The evolution of the average wage rate follows:

$$
w(S)=\left(1-\theta_{w}\right) w\left(S^{-}\right)+\theta_{w} \widetilde{w}(S)
$$

where $w\left(S^{-}\right)$denotes the average wage rate last period. Note that Equation (58) implies that those who just became employed negotiate their wage with probability $\theta_{w}$. Otherwise, they receive last period's average wage rate $w\left(S^{-}\right)$.

\footnotetext{
${ }^{11}$ We measure the wage and labor share in terms of the tradable goods, which serve as the numeraire.
} 
For households and firms, only the average wage rate $w(S)$ matters, and therefore, their problems are unchanged. The difference lies in the process of Nash bargaining. Under wage stickiness, the marginal value of a worker for the household with an average wage differs from the value of a worker with a newly set wage. Let $\widetilde{V}(w, S)$ be the value of a worker for the household if they just bargain the wage rate at $w$ :

$$
\begin{aligned}
\widetilde{V}(w, S)=w u_{c_{T}}(S)-\varsigma+(1-\lambda) \mathbb{E}\left\{\beta\left(1-\theta_{w}\right) \widetilde{V}\left(w, S^{\prime}\right)\right. & \left.+\beta \theta_{w} \widetilde{V}\left(\widetilde{w}\left(S^{\prime}\right), S^{\prime}\right) \mid \theta\right\} \\
& -\Phi^{w}\left[Q^{e}(S)\right] \mathbb{E}\left\{\beta V_{n}\left(S^{\prime}\right) \mid \theta\right\}
\end{aligned}
$$

Notice that the wage rate may be the same next period with probability $\theta_{w}$ or may become the newly set wage $\widetilde{w}\left(S^{\prime}\right)$. The value of a worker with a newly set wage rate $w$ for firms in the nontradable sector is

$$
\widetilde{J}^{N}(w, S)=\Psi^{f}\left[Q^{g}(S)\right] p(S) F_{n}^{N}(S) \frac{1}{\rho}-w+\frac{(1-\lambda)}{1+r} \mathbb{E}\left\{\left(1-\theta_{w}\right) \widetilde{J}^{N}\left(w, S^{\prime}\right)+\theta_{w} \widetilde{J}^{N}\left(\widetilde{w}\left(S^{\prime}\right), S^{\prime}\right) \mid \theta\right\}
$$

and for firms in tradable sector is

$$
\widetilde{J}^{T}(w, S)=F_{n}^{T}(S)-w-\phi_{n}^{T, n}(S)+\frac{(1-\lambda)}{1+r} \mathbb{E}\left\{\left(1-\theta_{w}\right) \widetilde{J}^{T}\left(w, S^{\prime}\right)+\theta_{w} \widetilde{J}^{T}\left(\widetilde{w}\left(S^{\prime}\right), S^{\prime}\right) \mid \theta\right\} .
$$

As in the baseline economy, we maintain the assumption that the value of a worker for firms is a weighted value of the evaluation of the worker by the firms with weights given by the employment share of each sector. Recall that $\chi(S)=\frac{n_{N}}{n_{N}+n_{T}}$ is the employment share of the nontradable sector. Then, the Nash bargaining problem is

$$
\widetilde{w}(S)=\max _{w}[\widetilde{V}(w, S)]^{\varphi}\left[\chi(S) \widetilde{J}^{N}(w, S)+(1-\chi(S)) \widetilde{J}_{n}^{T}(w, S)\right]^{1-\varphi} .
$$

Taking the derivative with respect to $w$ yields the first order condition

$$
\varphi \widetilde{V}_{w}(w, S)\left[\chi(S) \widetilde{J}^{N}(w, S)+(1-\chi(S)) \widetilde{J}^{T}(w, S)\right]=(1-\varphi) \frac{1+r}{r+\lambda+\theta_{w}-\lambda \theta_{w}} \widetilde{V}(w, S)
$$

where $V_{w}(w, S)$ is the discounted sum of marginal utility by increasing the wage rate by 1 unit:

$$
\widetilde{V}_{w}(w, S)=u_{c_{T}}(S)+\mathbb{E}\left\{\beta\left(1-\theta_{w}\right)(1-\lambda) \widetilde{V}_{w}\left(w, S^{\prime}\right) \mid \theta\right\}
$$


If the probability of bargaining, $\theta_{w}=1$, is set to one, then the staggered wage contract protocol collapses to the baseline case. If $\theta_{w}=0$, then the economy-wide wage rate will remain at its steady-state level forever.

We set $\theta_{w}=12.5 \%$, so that the average duration of a wage contract is one year. The third row of Table 4 displays the required shock size and the decomposition of the fall in output into labor and productivity. The required size of the shock is much smaller than in the baseline, less than half. Moreover, most of the fall in output is due to a fall in employment. The drop in consumption is also much smaller.

Figure 3 compares the impulse responses to the patience shock in the baseline and in the staggered wage economies. There are large differences among them. Staggered wages imply a faster recovery, the aforementioned lower drop in productivity and larger drop in employment (although it eventually becomes larger than the steady-state value), lower drops in consumption, investment, and in the price of nontradables, but lower increases in exports and in the long-run increase of wealth.

Both Staggered Wages and High Adjustment Costs Putting all the frictions together, that is, staggered wages and high adjustment costs, further reduces the required size of the shock to about $40 \%$ of that of the baseline (fourth row of Table 4 ). In this case, the drop in labor is as large as that of output.

\subsubsection{Model with Constant Labor Share}

The fifth row of Table 4 indicates that we are under the presence of an intermediate case between Nash bargaining wage setting and staggered wages. The size of the shock is about $60 \%$ of that of the baseline with employment dropping three-fourths as much as output.

\section{The Role of Adjustment Costs and Frictions in the Labor Market}

We now show that both adjustment costs and labor market frictions are necessary ingredients to create a recession when households want to save more in versions of the growth model with flexible prices. 
Figure 3

Impulse Responses in the Baseline and Staggered Wage Economies

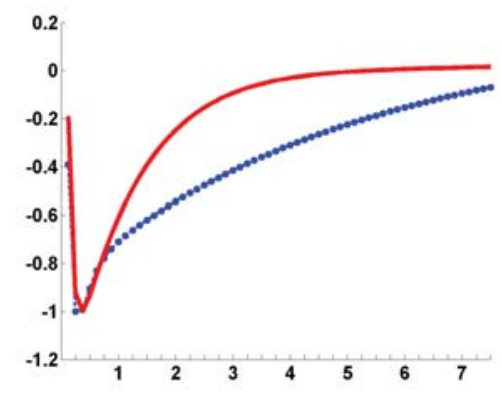

Real output

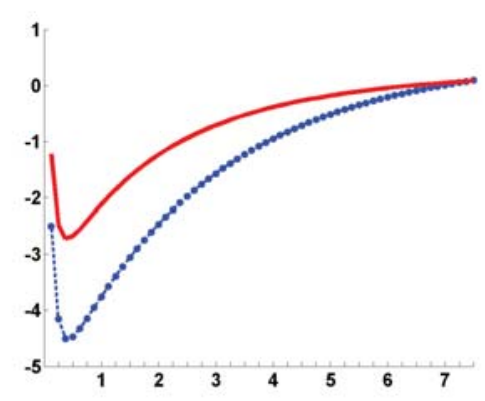

Consumption

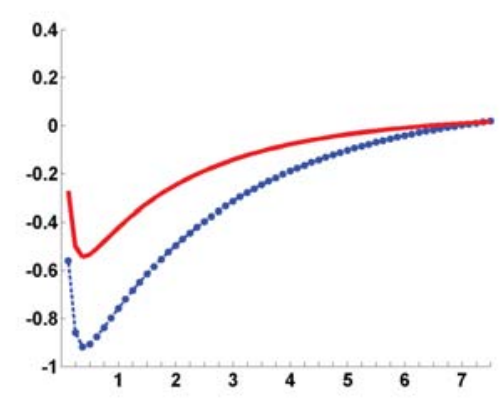

Number of varieties

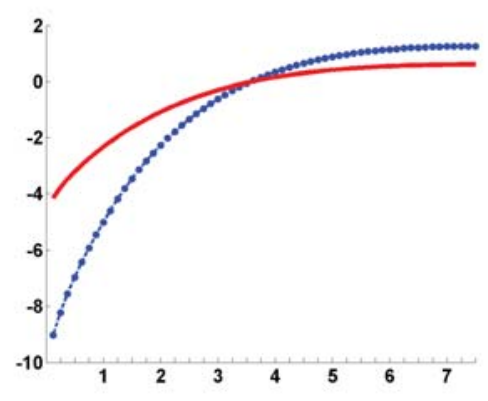

Investment

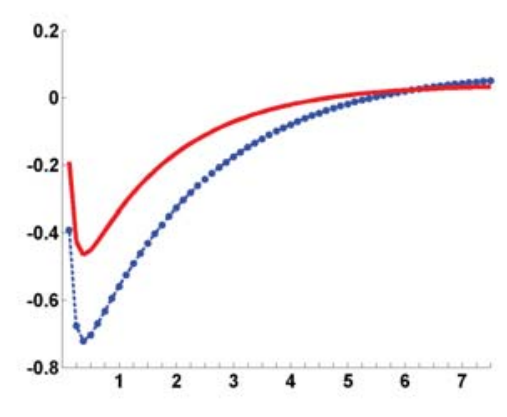

Solow residual

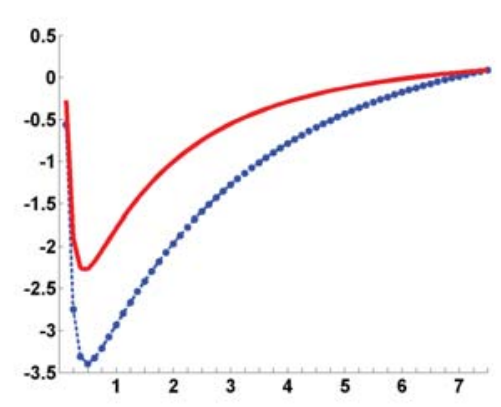

Output of nontradable

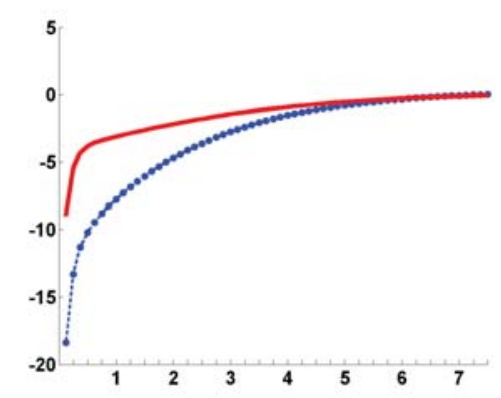

Price for nontradable

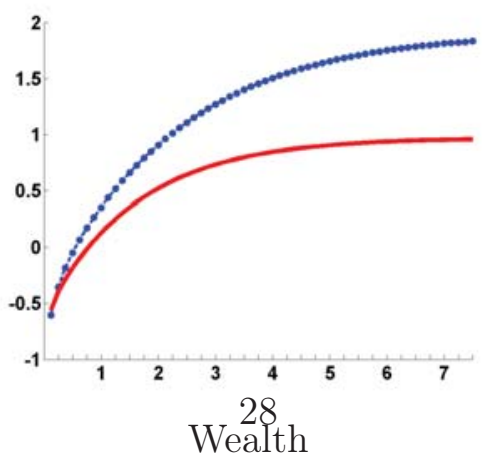

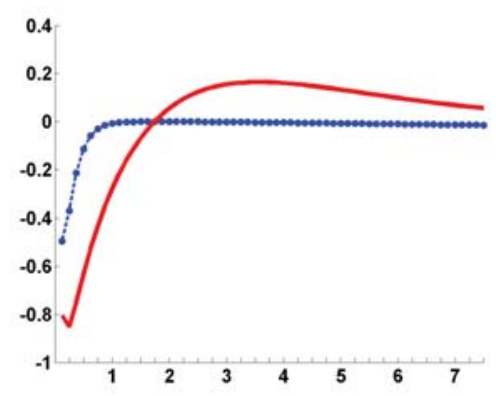

Employment

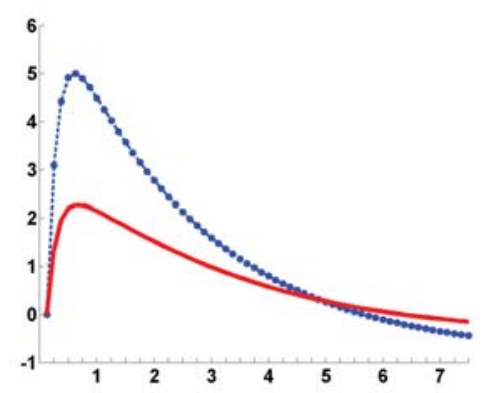

Output of tradable

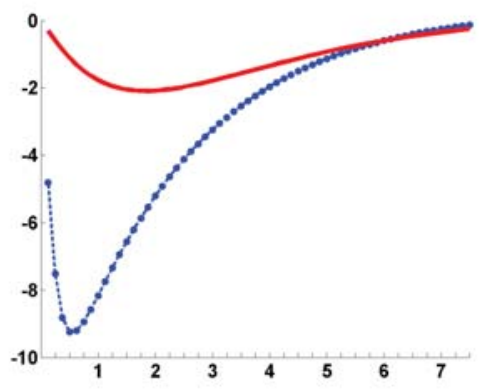

Wage

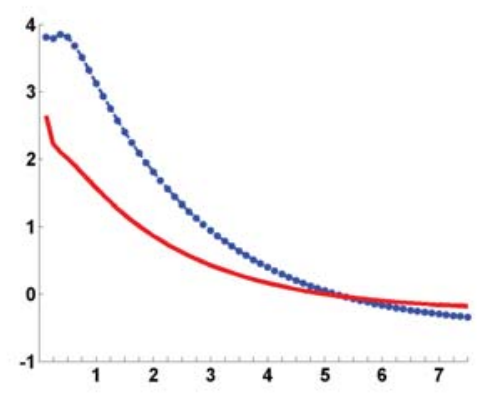

Net export/output ratio 
Adjustment Costs To see how nontrivial adjustment costs are necessary, it suffices to explore an economy with low adjustment costs. The sixth row of Table 4 displays such an economy. It is like the baseline except that adjustment costs are smaller. In fact, the only change is to have $\epsilon^{T, k}=\epsilon^{T, n}=0.10$. This implies that when facing a desire to increase savings that generates a 1 percent drop in output, the tradable sector expands by $12 \%$. In this case, the economy has a recession in terms of output but an increase in employment that peaks at $0.35 \%$. Clearly, if adjustment costs are low, employment will go up, while whether output goes up or down depends on the size of the shopping friction.

Frictions in the Labor Market The labor market friction prevents the household from choosing how much to work. Except when using GHH-type preferences between consumption and labor, a temporary increase in the discount rate induces households to be willing to reduce consumption and increase labor today relative to tomorrow. If households are able to choose how much to work, the economy will yield an increase in labor generating an expansion and not a recession. ${ }^{12}$ With our choice of preferences (separable preferences between consumption and leisure), a temporary reduction of the discount rate is what generates a recession. Figure 7 and the seventh and eighth rows of Table 4 show the performance of two versions of the baseline economy that have no labor market frictions (we look at a version both with and without goods markets frictions), and we can compare them with the performance of the baseline economy. Except for output and employment, all the other aggregate variables move in the opposite direction from the baseline. The recession is generated by a desire to enjoy utility today, with households wanting to consume more and work less. The tradable sector shrinks due to higher labor costs, but the nontradable sector expands because of the increase in nontradable prices due to the increase in demand despite the increase in wages. The shock needed to induce a $1 \%$ decrease in output is larger when the goods market friction exists. This is because the larger demand for nontradable goods also increases the Solow residual, which is countercyclical in this context. ${ }^{13}$

\section{The Role of Frictions in the Goods Market}

We now ask the quantitative importance of the mechanism that is the main technical contribution of this paper, a particular type of search friction in the goods markets that makes increases in

\footnotetext{
${ }^{12}$ The traditional way to avoid this problem is to assume wage or price stickiness as in most New Keynesian models. Recent practice includes Midrigan and Philippon (2011), Guerrieri and Lorenzoni (2011), SchmittGrohe and Uribe (2011), and Heathcote and Perri (2012).

${ }^{13}$ In Guerrieri and Lorenzoni (2011), after an adverse financial condition shock, output decreases, even though total labor increases due to a misallocation effect.
} 
savings cause declines in productivity. We pose an economy like the baseline except that there are no search frictions in the goods market, and therefore, consumers use all varieties and the economy works at full capacity.

The ninth line in Table 4 shows that to get a 1\% recession, the size of the shock required in an economy without the goods market friction is $2.59 \%$, about 2.5 times larger than in the baseline, a very large number. Moreover, such a recession is made up of a $1.25 \%$ reduction in employment and a .20\% reduction in TFP (which comes from the decreasing returns to scale of the tradable goods sector). In nonshopping versions of economies with high adjustment costs, staggered wages, and constant labor share, reported in rows 10 through 12 of Table 4, the size of the shock is also much larger than in their shopping counterpart.

Figure 4 shows the dynamic paths of this economy. In the absence of the shopping friction, the requirements for the recession are dramatic: a reduction of consumption of $9 \%$ rather than $4 \%$, a reduction of investment of $22 \%$ rather than $10 \%$, and also enormous reductions in the wage rate (over 20\%) and in the price of nontradables (over 40\%). We conclude that the contribution of consumers to the determination of productivity is a major ingredient for the understanding of business cycles.

\section{Models with Financial Frictions}

Clearly, shocks to patience are not what we have in mind as a trigger for an increased desire to save. ${ }^{14}$ We now extend our model to allow a limited form of heterogeneity within the household that is capable of accommodating shocks to the financial system that trigger changes in savings. Specifically, we assume that there are financial costs to provide insurance to unemployed workers, and therefore employed workers and unemployed workers may have different consumption levels. These costs are smaller when wealth is higher, as the transfers of the employed to the unemployed become smaller. Assume there is a cost $\psi$ per unit of transfer to unemployed workers. A relatively permanent increase of the financial cost $\psi$ makes it more expensive to insure unemployed workers, which encourages the household to increase savings. We will show that a shock to $\psi$ has effects similar to a shock to the discount factor $\beta$.

We now consider two specifications of the model with financial frictions, one in which employed

\footnotetext{
${ }^{14}$ This increase in financial frictions could also happen in a more standard manner within the context of a Aiyagari-Bewley-Huggett-Imrohoroglu heterogeneous agent type model.
} 
FIGURE 4

Impulse Responses in the Baseline Economy and the Economy without Goods Markets Frictions

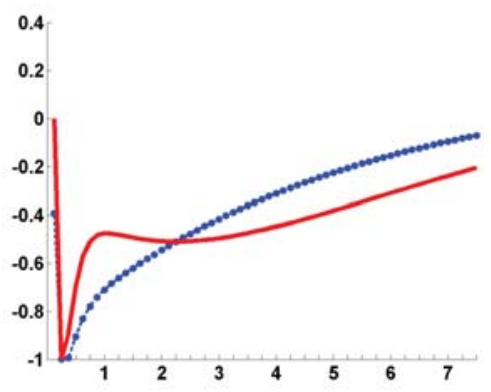

Real output

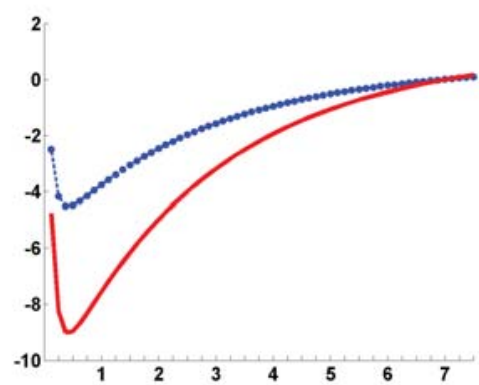

Consumption

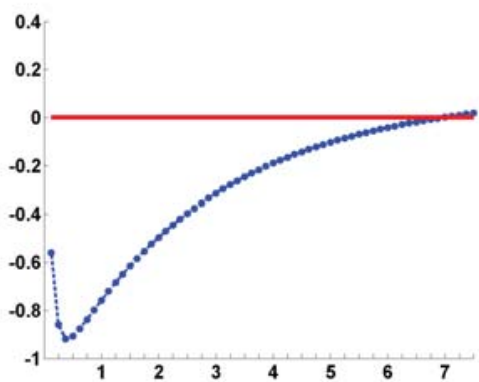

Number of varieties

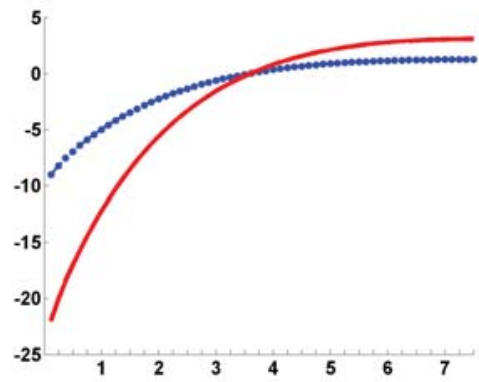

Investment

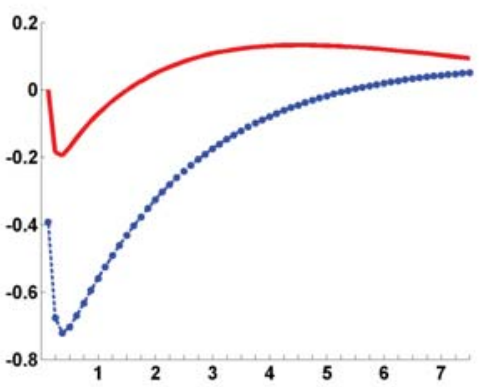

Solow residual

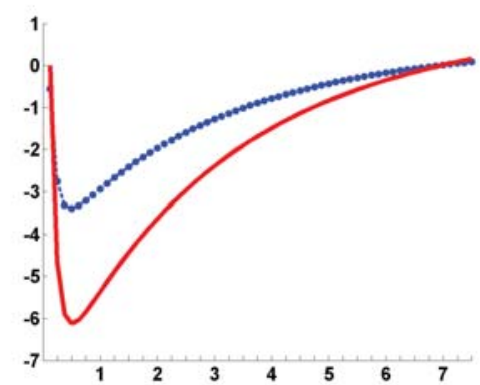

Output of nontradable

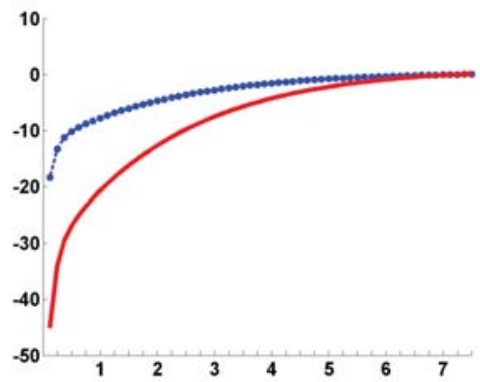

Price for nontradable

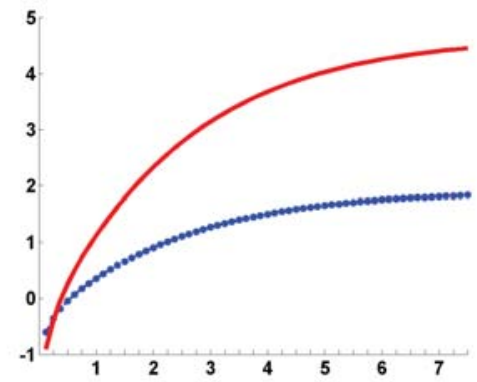

Wealth

31

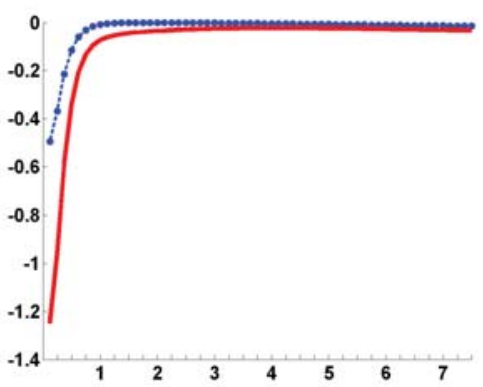

Employment

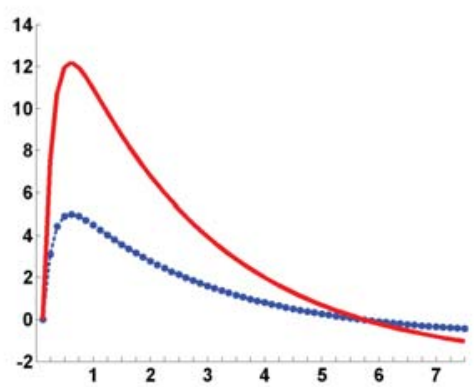

Output of tradable

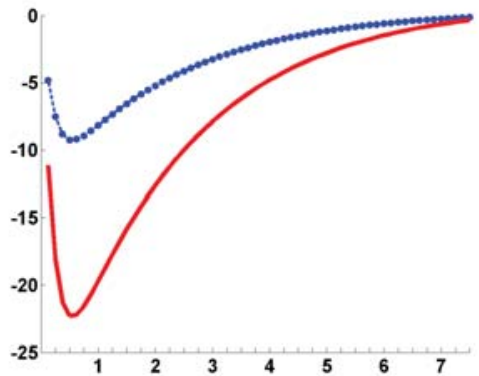

Wage

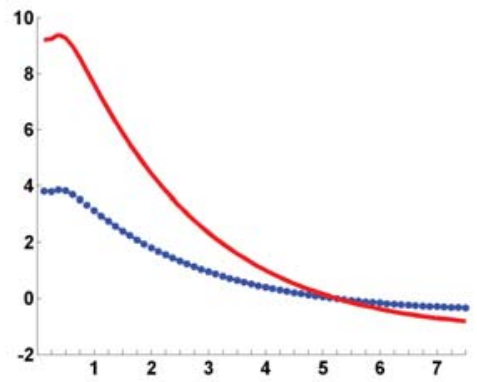

Net export/output ratio

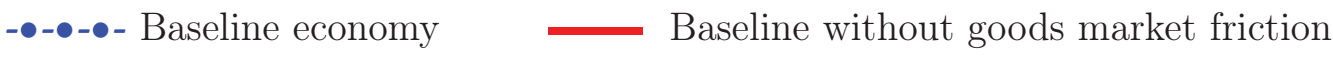


and unemployed workers may have different levels of consumption but have to exert the same shopping efforts and obtain the same number of varieties (Section 8.1). We refer to this economy as the financial frictions economy with nonsegmented markets (Financial Frictions I). The second version allows the two groups of agents to search in different goods markets with different prices, different market tightness, and different amounts consumed (Section 8.2, Financial Frictions II). In other words, goods markets can be segmented. We think of these two versions as extreme cases of a general version in which there are different goods markets for the two type of agents but some noise sends them to the wrong market. Since, as we will see, the quantitative results of these two specifications are very similar, we conclude that for the questions at hand, the precise specification does not matter that much.

\subsection{Financial Frictions I: Nonsegmented Goods Markets}

In this case, financial frictions occur between shopping and consuming, meaning that the prices faced and the number of varieties used by both employed and unemployed workers is the same. In other words, shoppers first buy a certain amount of goods at each firm and then distribute the goods to the two groups of workers. The amount of goods bought at each location is simply $n c_{N}^{e}+(1-n) c_{N}^{u}$, where $e$ and $u$ stand for employed and unemployed, respectively. In the absence of financial frictions, the household would equate consumption between employed and unemployed workers, but financial frictions induce it to provide different amounts of consumption. The problem of the household is now

$$
V(S, b, n)=\max _{c_{N}^{e}, c_{T}^{e}, c_{N}^{u}, c_{T}^{u}, I_{N}, d} n u\left(c_{A}^{e}, d, 1\right)+(1-n) u\left(c_{A}^{u}, d, 0\right)+\beta \mathbb{E}\left\{V\left(S^{\prime}, b^{\prime}, n^{\prime}\right) \mid \theta\right\}
$$

subject to

$$
\begin{aligned}
n\left[p(S) \mathrm{I}_{N} c_{N}^{e}+c_{T}^{e}\right]+ & \\
(1-n)\left[p(S) \mathrm{I}_{N} c_{N}^{u}+c_{T}^{u}\right] & =(1+r) b+w(S) n+\pi_{N}(S)+\pi_{T}(S)-\psi(1-n) \mathrm{T}_{r}-b^{\prime} \\
\mathrm{T}_{r} & =p(S) \mathrm{I}_{N} c_{N}^{u}+c_{T}^{u}-\left[(1+r) b+\pi_{N}(S)+\pi_{T}(S)\right] \\
\mathrm{I}_{N} & =\Psi^{d}\left[Q^{g}(S)\right] d \\
n^{\prime} & =(1-\lambda) n+\Phi^{w}\left[Q^{e}(S)\right](1-n), \\
S^{\prime} & =G(S) .
\end{aligned}
$$


The total consumption expenditures of each unemployed worker are $p(S) \mathrm{I}_{N} c_{N}^{u}+c_{T}^{u}$ and the financial assets available to each worker are bond holdings plus the profits from firms $(1+r) b+\pi_{N}(S)+$ $\pi_{T}(S)$. In the budget constraint, the transfer to an unemployed worker is $T_{r}$, the difference between consumption and per agent financial assets, and the financial costs of this transfer are $\psi(1-n) \mathrm{T}_{r}$. When the household accumulates more savings, the financial costs to achieve the same consumption for the unemployed are smaller. The first order conditions are

$$
\begin{aligned}
u_{c_{N}^{e}} & =p(S) \mathrm{I}_{N} u_{c_{T}^{e}}, \\
u_{c_{N}^{u}} & =p(S) \mathrm{I}_{N} u_{c_{T}^{u}}, \\
u_{c_{T}^{e}} & =u_{c_{T}^{u}}(1+\psi), \\
n\left[u_{\mathrm{I}_{N}}^{e}-p(S) c_{N}^{e} u_{c_{T}^{e}}+\frac{u_{d}^{e}}{\Psi^{d}\left[Q^{g}(S)\right]}\right] & =-(1-n)\left[u_{\mathrm{I}_{N}}^{u}-p(S) c_{N}^{u} u_{c_{T}^{u}}+\frac{u_{d}^{u}}{\Psi^{d}\left[Q^{g}(S)\right]}\right], \\
u_{c_{T}^{e}} & =(1+r) \mathbb{E}\left\{\beta u_{c_{T}^{e}}^{\prime}\left[1+\psi^{\prime}\left(1-n^{\prime}\right)\right] \mid \theta\right\} .
\end{aligned}
$$

Equations (71) and (72) describe the optimality condition between tradables and nontradables. Equation (73) implies that unless financial costs are zero, i.e, $\psi=0$, the consumption level of the employed will be higher than the unemployed. The inequality is increasing in $\psi$. In the baseline economy, the optimal choice of $\mathrm{I}_{N}$ equalizes the benefits of one variety and the cost of its associated shopping disutility. With two groups sharing the same number of varieties, the optimal $I_{N}$ equalizes a weighted average of costs and benefits, with the weights given by the employment rate. Equation (75) is the Euler equation, which we write in terms of consumption of the employed. The problems of the firms are the same as in the baseline economy, except that aggregate demand is now $C_{N}(S)=n C_{N}^{e}(S)+(1-n) C_{N}^{u}(S)$.

We calibrate $\psi$ such that in the steady state, the financial cost $\psi(1-n) \mathrm{T}_{r}$ accounts for $1 \%$ of output, although what matters is not the steady state level but the size of the shocks. ${ }^{15}$ We assume that $\psi$ follows an $\operatorname{AR}(1)$ process with persistence of 0.95 . The size of the shock is chosen to get a $1 \%$ real output drop.

We can log-linearize the Euler equation (75) as

$$
\widehat{u}_{c_{T}^{e}, t}=\widehat{u}_{c_{T}^{e}, t+1}+\frac{\psi^{*}\left(1-n^{*}\right)}{1+\psi^{*}\left(1-n^{*}\right)} \widehat{\psi}_{t+1}-\frac{\psi^{*} n^{*}}{1+\psi^{*}\left(1-n^{*}\right)} \widehat{n}_{t+1}
$$

\footnotetext{
${ }^{15}$ In the steady state, $\psi=0.28$. The calibration of other parameter values are similar to the baseline model and are found in Appendix E.
} 
where $\psi^{*}$ and $n^{*}$ are their steady-state values. We define $\widehat{\beta}$ as the wedge between the intertemporal marginal utility of consumption. Here, $\widehat{\beta}=\frac{\psi^{*}\left(1-n^{*}\right)}{1+\psi^{*}\left(1-n^{*}\right)} \widehat{\psi}_{t+1}-\frac{\psi^{*} n^{*}}{1+\psi^{*}\left(1-n^{*}\right)} \widehat{n}_{t+1}$. Recall that in the baseline economy with the discount factor shock, the log-linearized Euler equation is simply

$$
\widehat{u}_{c_{T}, t}=\widehat{u}_{c_{T}, t+1}+\tau_{t}
$$

with $\widehat{\beta}=\tau$. It can be seen that the effect of the shock to $\psi$ is similar to a shock to $\beta$. We then compare the implied $\widehat{\beta}$ with the shock to $\beta$ in the baseline economy. For the wage protocol, we adopt the one that permits a constant labor share. ${ }^{16}$

TABLE 5

Recession Statistics of the Financial Frictions Economies with Constant Labor Share

\begin{tabular}{lccccc}
\hline \hline Model economy & $\widehat{\beta}$ & Employment & TFP & Consumption & Cost/Output \\
\hline Baseline+constant labor share & 0.69 & -0.76 & -0.51 & -3.06 & - \\
Non-segmented goods markets (Fin Fr I) & 0.81 & -0.82 & -0.49 & -2.75 & 1.23 \\
Segmented goods markets (Fin Fr II) & 0.83 & -0.83 & -0.47 & -2.80 & 1.23 \\
\hline \hline
\end{tabular}

In the first two rows of Table 5, we compare the size of the shocks in terms of the explicit or implied proportional change in the discount factor. We use a version of the baseline economy with constant factor shares as well as the economies with financial shocks and constant factor shares. The value goes from $0.69 \%$ to $0.81 \%$. The financial cost to output ratio goes from $1 \%$ in steady state to $1.23 \%$ after the shock to $\psi$. The financial friction model has a slightly larger drop in employment and a milder decrease of the Solow residual.

Figure 5 compares the performance of the baseline economy with the one with financial frictions. The main difference besides the larger (but shorter) drop in employment and smaller drop in productivity is that the financial friction economy has less reallocation of resources and the final increase in assets is much smaller. As such, net exports go up to $2.5 \%$ of GDP, not $3 \%$, and the increase in total wealth is about $.7 \%$ and slowly disappears as the financial frictions return to normal.

\footnotetext{
${ }^{16}$ We do not use Nash bargaining because after a $\psi$ shock, one additional employed worker becomes much more valuable to the household, which greatly weakens the household's bargaining power and leads to an implausible decrease of wages.
} 


\subsection{Financial Frictions II: Multiple Nontradable Goods Markets}

In the previous model of financial frictions, employed and unemployed workers exert the same search effort, consume the same varieties, and face the same prices. We now relax this assumption to allow the two groups of agents to obtain different amounts of varieties and to face different prices. Like the retirees in Aguiar and Hurst (2005), the unemployed workers are willing to search at a higher intensity and value lower prices more than working agents, which generates a rationale for firms to provide a limited form of price discrimination. Firms will gear some of their locations to cater to unemployed workers and the rest to employed workers. The former will face higher market tightness and lower prices, but, as it turns out, not lower quantities of each good. This is clearly an implication of the stark assumption that firms could perfectly discriminate. Any noise in the market that agents encounter will create an economy that is a combination of differences in both prices and quantities.

Let $X$ denote the fraction of locations that cater to shoppers sent by employed workers. Denote by $D^{e}$ and $D^{u}$ the aggregate shopping effort of the employed and unemployed. Tightness in both goods markets, $Q^{g, e}$ and $Q^{g, u}$, is

$$
Q^{g, e}=\frac{X}{n D^{e}}, \quad Q^{g, u}=\frac{1-X}{(1-n) D^{u}},
$$

with associated probabilities $\Psi^{d}\left(Q^{g, e}\right)$ and $\Psi^{d}\left(Q^{g, u}\right)$ for shoppers and $\Psi^{f}\left(Q^{g, e}\right)$ and $\Psi^{f}\left(Q^{g, u}\right)$ for firms. The price indices for the two groups are $p^{e}$ and $p^{u}$. The problem of the household is

$$
\begin{aligned}
& V(S, b, n)=\max _{\substack{c_{N}^{e}, c_{C}^{e}, I_{N}^{e}, d^{e} \\
c_{N}^{u}, c_{T}^{u}, I_{N}^{u}, d^{u}}} n u\left(c_{A}^{e}, d^{e}, 1\right)+(1-n) u\left(c_{A}^{u}, d^{u}, 0\right)+\beta \mathbb{E}\left\{V\left(S^{\prime}, b^{\prime}, n^{\prime}\right) \mid \theta\right\} \quad \text { s.t. } \\
& n\left[p^{e}(S) \mathrm{I}_{N}^{e} c_{N}^{e}+c_{T}^{e}\right]+ \\
& (1-n)\left[p^{u}(S) \mathrm{I}_{N}^{u} c_{N}^{u}+c_{T}^{u}\right]=(1+r) b+w(S) n+\pi_{N}(S)+\pi_{T}(S)-\psi(1-n) \mathrm{T}_{r}-b^{\prime} . \\
& \mathrm{T}_{r}=p^{u}(S) \mathrm{I}_{N}^{u} c_{N}^{u}+c_{T}^{u}-\left[(1+r) b+\pi_{N}(S)+\pi_{T}(S)\right] \\
& \mathrm{I}_{N}^{e}=\Psi^{d}\left[Q^{g, e}(S)\right] d^{e} \text {, } \\
& \mathrm{I}_{N}^{u}=\Psi^{d}\left[Q^{g, u}(S)\right] d^{u} \text {, } \\
& n^{\prime}=(1-\lambda) n+\Phi^{w}\left[Q^{e}(S)\right](1-n) \text {, } \\
& S^{\prime}=G(S) \text {. }
\end{aligned}
$$


The first order conditions are the same as in the previous financial friction economy, with the exception that there are two separate optimality conditions for the choice of the number of varieties:

$$
\begin{aligned}
& u_{\mathrm{I}_{N}^{e}}=p^{e}(S) c_{N}^{e} u_{c_{T}^{e}}-\frac{u_{d^{e}}}{\psi^{d}\left[Q^{g, e}(S)\right]} \\
& u_{\mathrm{I}_{N}^{u}}=p^{u}(S) c_{N}^{u} u_{c_{T}^{u}}-\frac{u_{d^{u}}}{\psi^{d}\left[Q^{g, u}(S)\right]} .
\end{aligned}
$$

The problem of a nontradable firm $i$ involves choosing the fraction of locations $x_{i}$ producing for the employed and also determining how much to produce at each location. In equilibrium, firms are indifferent between producing for the two types of agents, which implies that

$$
p^{e}(S) \Psi^{f}\left[Q^{g, e}(S)\right]=p^{u}(S) \Psi^{f}\left[Q^{g, u}(S)\right]
$$

And the price for nontradables adjusts in a way such that

$$
c_{N}^{e}=c_{N}^{u}
$$

Clearly, in order to satisfy the two conditions at the same time, it must be the case that $p^{e}(S)>$ $p^{u}(S)$ and $\Psi^{f}\left[Q^{g, e}(S)\right]<\Psi^{f}\left[Q^{g, u}(S)\right]$. On the one hand, the employed workers shop at locations with a shorter waiting line, but they pay a higher price. On the other hand, the unemployed workers would like to pay a lower price but search harder. This is a natural result with directed search, as obtained in Bai, Ríos-Rull, and Storesletten (2011). After the shock to $\psi$, both employed and unemployed workers reduce the amount of consumption by reducing both the amount of consumption at each location and the number of varieties consumed. The unemployed workers reduce their shopping effort to a lesser extent compared with employed workers, but $\mathrm{I}_{N}^{u}$ decreases more than $\mathrm{I}_{N}^{e}$ due to a lower probability of finding a location.

The quantitative behavior of the main aggregate variables is similar to the other economy with financial frictions, as can be seen in Figure 5 and the last row of Table 5. The implied $\widehat{\beta}$ increases by $0.83 \%$, and the financial cost to output ratio increases by $23 \%$.

\section{Shocks to Wealth}

In this section, we look for a different mechanism to trigger a recession. Instead of having a steady state with a zero net foreign asset position, assuming the economy has now a large negative asset 
FIGURE 5

Impulse Responses in the Baseline and Financial Friction Economies

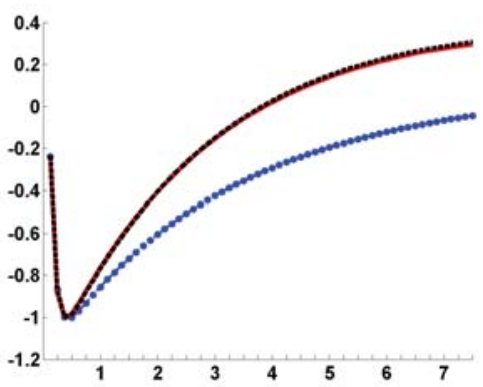

Real output

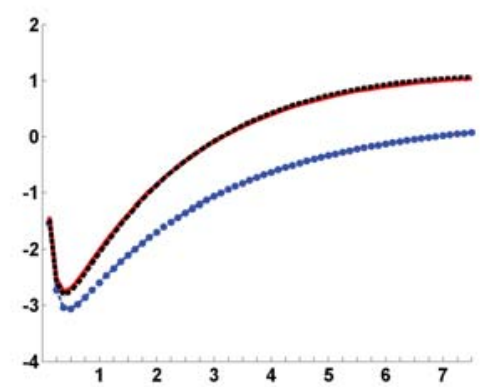

Consumption

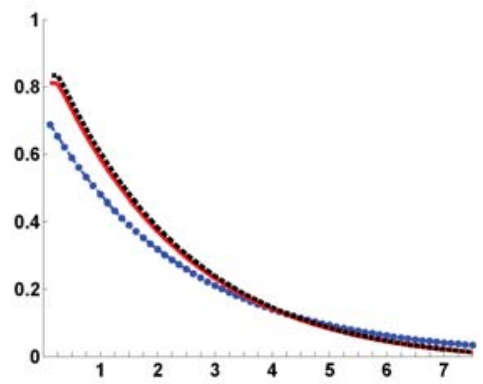

Discount factor $\widehat{\beta}$

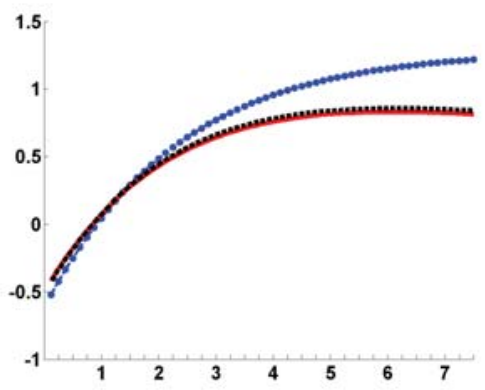

Wealth

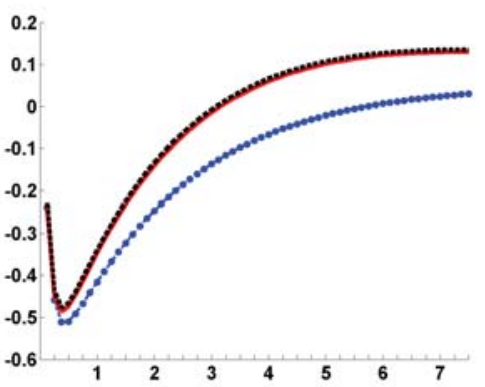

Solow residual

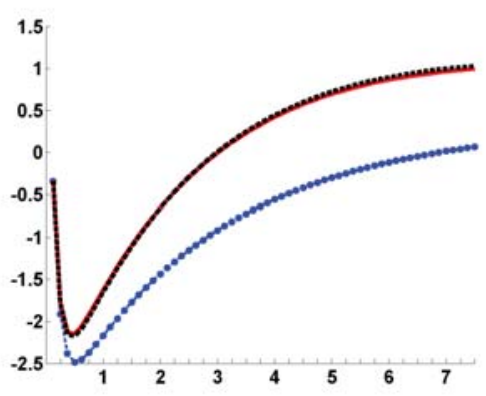

Output of nontradable

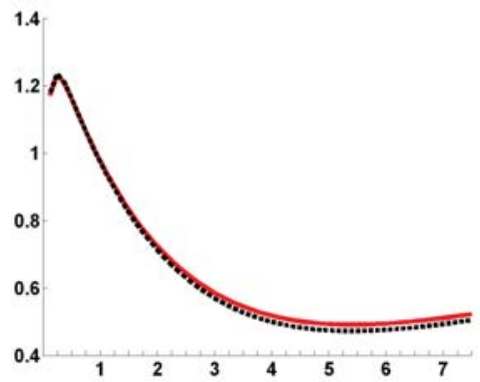

Financial cost/output ratio

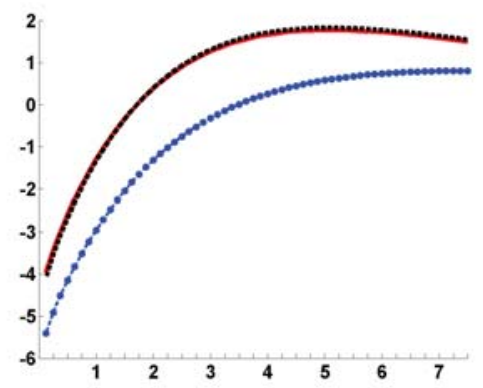

Investment

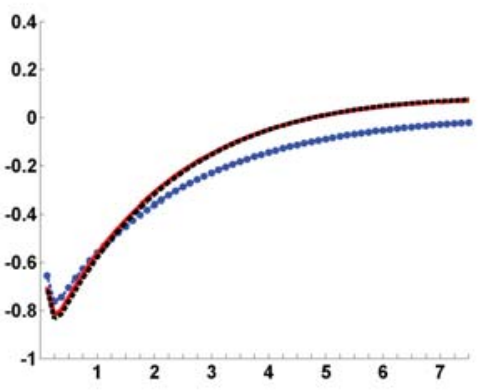

Employment

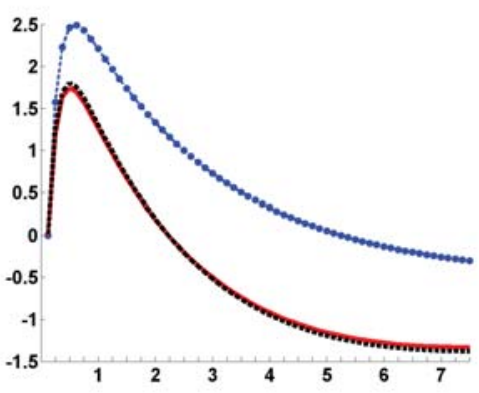

Output of tradable

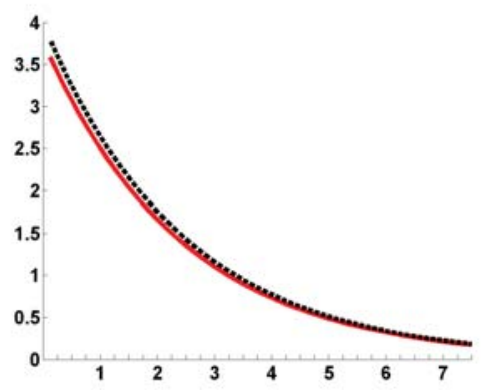

Ratio of $C_{e}$ to $C_{u}$

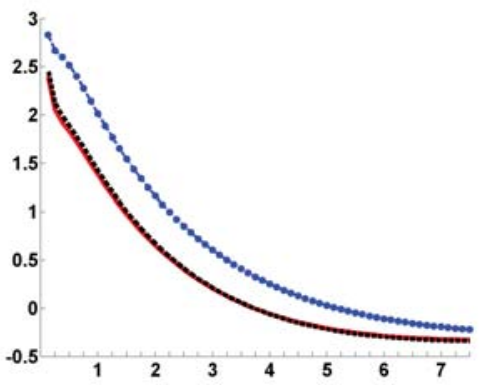

Net export/output ratio 
position (this can be seen as a wealth destruction shock). We now engineer a recession by finding out which value of net foreign asset position induces $1 \%$ less output in the long run than the steady state of the economy, which has a zero net foreign asset position. This exercise tries to capture the implication that when households become impoverished, they lower their consumption bringing about a permanent drop in output and the Solow residual. The shock enters the households' budget constraint as an unexpected one-time shock $\epsilon^{w}$ in the following way:

$$
p(S) c_{N} \mathrm{I}_{N}+c_{T}+b^{\prime}=(1+r)\left(b-\epsilon^{w}\right)+w(S) n+\pi_{N}(S)+\pi_{T}(S)
$$

In the first row of Table 6, we list the size of the shock as a percentage of initial total wealth. This is a large shock, since the total value of wealth in this economy is about 5 times the yearly outputs. The second row displays the needed size of the shock in a version of the economy without the shopping friction. Again, the latter is twice as large. Figure 6 covers the first 10 years after

TABLE 6

Statistics for Wealth Shock to Induce 1\% Output Drop

\begin{tabular}{lcccc}
\hline \hline Model economy & Wealth Shock & Employment & TFP & Consumption \\
\hline Baseline & 11.25 & -0.21 & -0.37 & -3.31 \\
Baseline, no shopping & 21.30 & -0.39 & -0.07 & -5.01 \\
\hline
\end{tabular}

the shock. Note now that the changes are permanent. The impoverishment requires that the economy reallocates resources into the tradable goods sector, resulting in a permanent expansion of tradable goods production and net exports. There is also a permanent decline in wages, which will encourage a permanent increase in employment, but only after a decline in the short run due to the adjustment costs.

\section{Robustness}

We now turn to examine the sensitivity of our results to alternative calibrations. We change the values of some key targets and parameters and compare the results with the baseline economy. Table 7 shows the main properties of the recession in these alternative economies. We first consider the elasticity of substitution between nontradables and tradables. A higher elasticity of substitution allows households to greatly reduce their consumption of tradables without reducing much of their 
Figure 6

Impulse Responses of Shocks to Wealth

in the Baseline Economy and in the Economy without Goods Markets Frictions

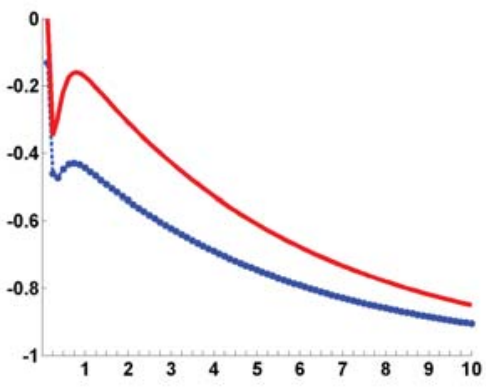

Real output

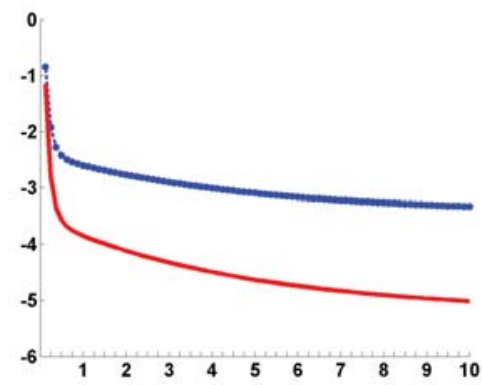

Consumption

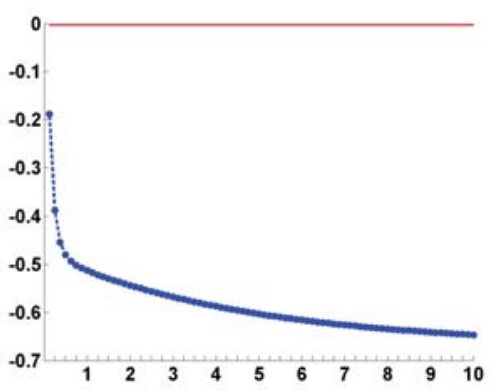

Number of varieties

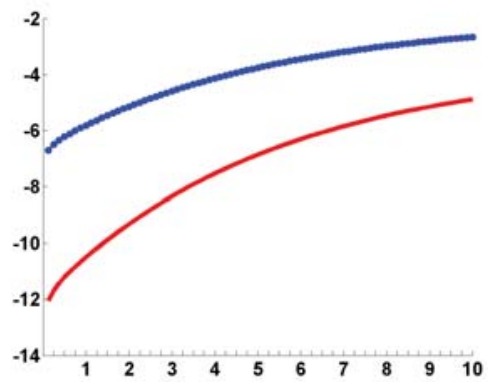

Investment

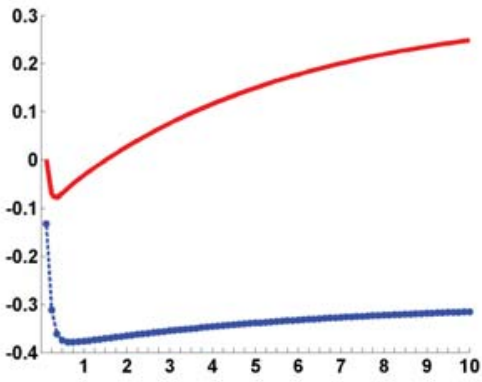

Solow residual

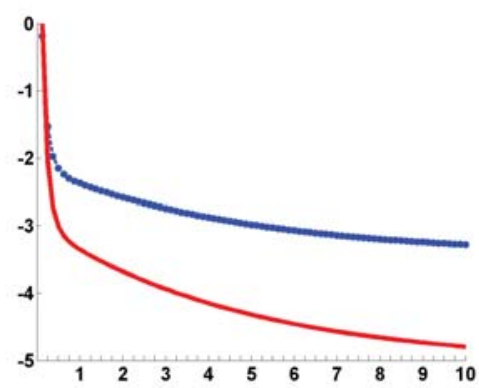

Output of nontradable

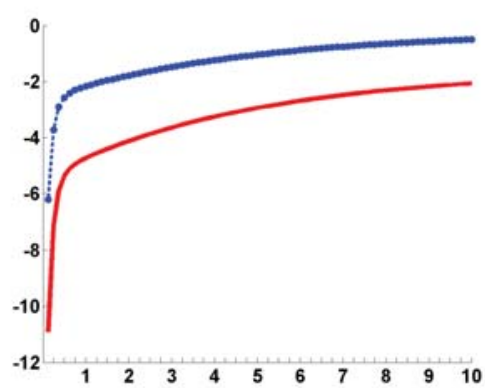

Price for nontradable

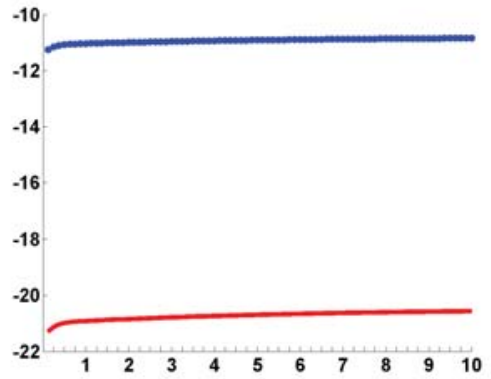

Weasth

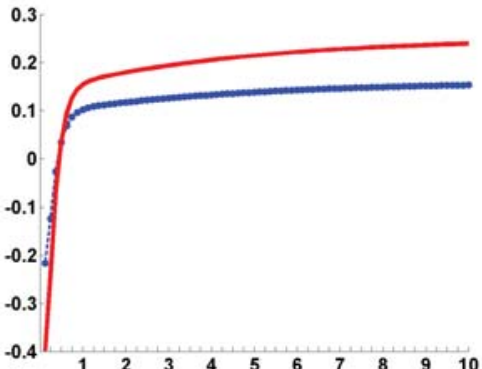

Employment

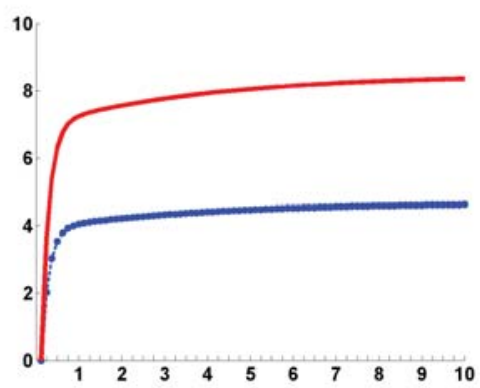

Output of tradable

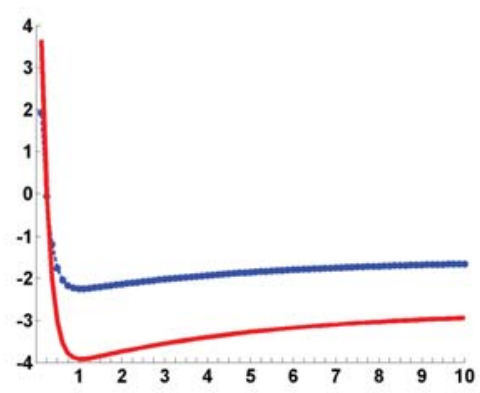

Wage

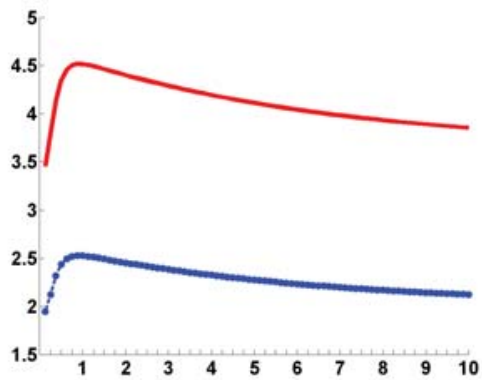

Net export/output ratio

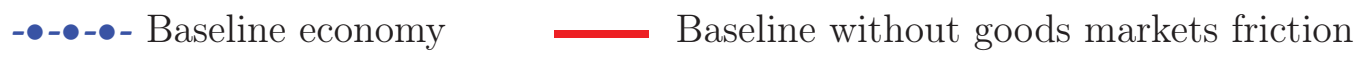


nontradables, which makes recessions harder to create. The required shock goes up by $7 \%$ when the elasticity of substitution goes up about $40 \%$. We conclude that the differences are small.

The issue of how to model bargaining process between workers and firms is still in debate in the labor market search literature. ${ }^{17}$ Most studies focus on the effect of productivity shocks on labor market volatility. Higher bargaining power for workers implies large wage volatility and low employment volatility. However, this argument cannot be carried over into the current environment. In this paper, the recession originates from changes in the willingness to enjoy consumption and leisure today versus tomorrow. These changes result in increased volatility of employment when the workers' weight is larger, which in turn implies that the required size of the shock is about $20 \%$ lower.

To see the effects of the labor market matching elasticity $\mu$, consider that for the same reduction in employment as in the baseline economy, a higher $\mu$ makes hiring a new worker cheaper. The total reallocation costs are also cheaper. As a result, to get the same size recession, a $20 \%$ larger initial shock is needed.

The role of goods market matching elasticity $\alpha$ is straightforward. For the same decrease in aggregate search effort, $D$, a higher matching elasticity $\alpha$ leads to a larger decline in the probability of meeting customers. Therefore, the Solow residual and aggregate output decrease further. The size of the shock needed to obtain a $1 \%$ recession is $25 \%$ smaller when $\alpha$ changes from 0.19 to 0.28 .

The elasticity of substitution between nontradable goods is $\frac{\rho}{\rho-1}$. A higher $\rho$ lowers the substitutability between the nontradable goods and increases the elasticity of the number of varieties $\mathrm{I}_{N}$ with respect to consumption per variety, $c_{N}$. In other words, with the same reduction in $c_{N}$, an economy with higher $\rho$ will have a larger drop in $\mathrm{I}_{N}$. As can be seen from Table 7 , the elasticity of $\mathrm{I}_{N}$ with respect to $c_{N}$ is largest when $\rho=1.08$, corresponding to a larger drop in the Solow residual and a smaller required shock to patience.

\section{Conclusion}

In this paper we have generated demand-induced recessions in an otherwise standard neoclassical growth model. The two necessary ingredients are (1) the costs of adjustment that make it difficult for the economy to reallocate factors of production from nontradables to tradables and (2) some

\footnotetext{
${ }^{17}$ See Hagedorn and Manovskii (2008) and Shimer (2005), for example.
} 
form of noncompetitive labor markets, with Morten-Pissarides labor search frictions and wage setting via Nash bargaining being enough. These recessions display the paradox of thrift in the sense that increases in savings reduce wealth on impact, and wealth starts to increase only after a few months. We also developed a model in which reductions in household consumption reduce measured TFP. The model poses frictions in the goods markets, with consumers' search effort helping to allow the economy to operate at higher capacity (an extension of the search model of Bai, Ríos-Rull, and Storesletten (2011)). The quantitative importance of this margin is emphasized because equal shocks generate recessions that are twice as large in economies with this margin. We have also extended our model to have increases in financial frictions act like increases in patience, generating recessions even in the context of a representative agent model. We think that the type of recession we have posed here resembles what is happening in southern Europe in many ways.

\section{References}

Aguiar, M., And E. Hurst (2005): "Consumption versus Expenditure," Journal of Political Economy, 113(5), 919-948.

(2007): "Life-Cycle Prices and Production," American Economic Review, 97(5), 15331559 .

Bai, Y., J.-V. Ríos-Rull, and K. Storesletten (2011): "Demand Shocks as Productivity Shocks," Working Paper, Federal Reserve Bank of Minneapolis.

Basu, S., And J. Fernald (1997): "Returns to Scale in U.S. Production: Estimates and Implications," Journal of Political Economy, 105(2), 249-283.

Bianchi, J. (2011): "Overborrowing and Systemic Externalities in the Business Cycle," American Economic Review, 101(7), 3400-3426.

Choi, S., and J.-V. Ríos-Rull (2008): "Understanding the Dynamics of Labor Share: The Role of Noncompetitive Factor Prices," Mimeo.

Christiano, L., M. Eichenbaum, and C. Evans (2005): "Nominal Rigidities and the Dynamic Effects of a Shock to Monetary Policy," Journal of Political Economy, 113(1), 1-45.

Christiano, L., M. Eichenbaum, and S. Rebelo (2011): "When Is the Government Spending Multiplier Large?," Journal of Political Economy, 119(1), 78-121. 
Corrado, C., And J. Mattey (1997): "Capacity Utilization," Journal of Economic Perspectives, 11(1), 151-167.

Correia, I., E. Farhi, J. P. Nicolini, and P. Teles (2011): "Unconventional Fiscal Policy at the Zero Bound," Forthcoming, American Economic Review.

Eggertsson, G. B. (2011): "What Fiscal Policy Is Effective at Zero Interest Rates?," in NBER Macroeconomics Annual, 25, 59-112, Chicago: University of Chicago Press.

Eggertsson, G. B., And P. Krugman (2012): "Debt, Deleveraging, and the Liquidity Trap: A Fisher-Minsky-Koo Approach," The Quarterly Journal of Economics, 127(3), 1469-1513.

FARhi, E., And I. Werning (2012): "Fiscal Unions," Working Paper, MIT Department of Economics.

Gertler, M., And A. Trigari (2009): "Unemployment Fluctuations with Staggered Nash Wage Bargaining," Journal of Political Economy, 117(1), 38-86.

Greenwood, J., Z. Hercowitz, and G. Huffman (1988): "Investment, Capacity Utilization, and the Real Business Cycle," American Economic Review, 78(3), 402-418.

Guerrieri, V., and G. Lorenzoni (2011): "Credit Crises, Precautionary Savings, and the Liquidity Trap," NBER Working Paper 17583.

Hagedorn, M., And I. Manovskir (2008): "The Cyclical Behavior of Equilibrium Unemployment and Vacancies Revisited," American Economic Review, 98(4), 1692-1706.

HALl, R. (2005): "Employment Fluctuations with Equilibrium Wage Stickiness," American Economic Review, 95(1), 50-65.

Heathcote, J., And F. Perri (2002): "Financial Autarky and International Business Cycles," Journal of Monetary Economics, 49(3), 601-627. (2012): "Wealth and Volatility," Mimeo.

Kehoe, T. J., and K. J. Ruhl (2009): "Sudden Stops, Sectoral Reallocations, and the Real Exchange Rate," Journal of Development Economics, 89(2), 235-249.

Krusell, P., T. Mukoyama, And A. ŞAhin (2010): “Labour-Market Matching with Precautionary Savings and Aggregate Fluctuations," Review of Economic Studies, 77(4), 1477-1507. 
Mendoza, E. G. (2001): "Credit, Prices, and Crashes: Business Cycles with a Sudden Stop," NBER Working Paper 8338.

Mendoza, E. G., And V. Z. Yue (2012): "A General Equilibrium Model of Sovereign Default and Business Cycles," The Quarterly Journal of Economics, 127(2), 889-946.

Merz, M. (1995): "Search in the Labor Market and the Real Business Cycle," Journal of Monetary Economics, 36(2), 269-300.

Mian, A., And A. Sufi (2010): "The Great Recession: Lessons from Microeconomic Data," American Economic Review, 100(2), 51-56.

Mian, A., And A. Sufi (2012): "What Explains High Unemployment? The Aggregate Demand Channel," Unpublished Manuscript, Booth School of Business.

Midrigan, V., And T. Philippon (2011): "Household Leverage and the Recession," Working Paper No. FIN-11-038, New York University.

Nakajima, M. (2012): "Business Cycles In The Equilibrium Model Of Labor Market Search And Self-Insurance," International Economic Review, 53(2), 399-432.

Rendahl, P. (2012): "Fiscal Policy in an Unemployment Crisis," Working Paper, University of Cambridge.

Schmitt-Grohe, S., And M. URIBE (2011): "Pegs and Pain," NBER Working Papers 16847.

Schmitt-Grohe, S., And M. Uribe (2012): "The Making of a Great Contraction with a Liquidity Trap and a Jobless Recovery," NBER Working Paper 18544.

Shimer, R. (2005): "The Cyclical Behavior of Equilibrium Unemployment and Vacancies," American Economic Review, 95(1), 25-49.

Shimer, R. (2012): "Wage Rigidities and Jobless Recoveries," Forthcoming in Journal of Monetary Economics.

Silva, J. I., And M. Toledo (2009): "The Unemployment Volatility Puzzle: The Role of Matching Costs Revisited," Mimeo. 
TABLE 7

Sensitivity Analysis

Elasticity of substitution between nontradable and tradable

\begin{tabular}{lcccc}
\hline Parameter & Pref Shock & Employment & TFP & Tradable consumption \\
\hline$\eta=0.83$ & 1.12 & -0.50 & -0.72 & -15.89 \\
$\eta=1.20$ & 1.20 & -0.49 & -0.73 & -22.34 \\
$\eta=0.60$ & 1.07 & -0.50 & -0.72 & -11.73 \\
\hline
\end{tabular}

Bargaining power of workers

\begin{tabular}{lcccc}
\hline Parameter & Pref shock & Employment & TFP & Wage rate \\
\hline$\varphi=0.35$ & 1.12 & -0.50 & -0.72 & -9.25 \\
$\varphi=0.50$ & 0.93 & -0.62 & -0.63 & -6.90 \\
$\varphi=0.20$ & 1.65 & -0.10 & -0.96 & -16.38 \\
\hline
\end{tabular}

Labor market matching elasticity

\begin{tabular}{lcccc}
\hline Parameter & Pref shock & Employment & TFP & Elast of $N_{N}$ wrt $N_{T}$ \\
\hline$\mu=0.50$ & 1.12 & -0.50 & -0.72 & -57.62 \\
$\mu=0.70$ & 1.32 & -0.29 & -0.81 & -50.07 \\
$\mu=0.40$ & 0.97 & -0.58 & -0.66 & -62.87 \\
\hline
\end{tabular}

Goods market matching elasticity

\begin{tabular}{lcccc}
\hline Parameter & Pref Shock & Employment & TFP & Number of varieties \\
\hline$\alpha=0.19$ & 1.12 & -0.50 & -0.72 & -0.92 \\
$\alpha=0.28$ & 0.84 & -0.35 & -0.81 & -1.08 \\
$\alpha=0.12$ & 1.46 & -0.67 & -0.60 & -0.71 \\
\hline
\end{tabular}

Elasticity of substitution between nontradable goods

\begin{tabular}{lcccc}
\hline Parameter & Pref Shock & Employment & TFP & Elast of $\mathrm{I}_{N}$ wrt $c_{N}$ \\
\hline$\rho=1.05$ & 1.12 & -0.50 & -0.72 & 45.35 \\
$\rho=1.08$ & 1.05 & -0.45 & -0.75 & 48.18 \\
$\rho=1.02$ & 1.20 & -0.55 & -0.68 & 41.99 \\
\hline
\end{tabular}




\section{Appendix}

\section{A Simplification of the Household's Problem}

The original problem for households is

$$
V(S, b, n)=\max _{c_{N, i}, c_{T}, \mathrm{I}_{N}, d} u\left(c_{A}, d, n\right)+\beta \mathbb{E}\left\{V\left(S^{\prime}, b^{\prime}, n^{\prime}\right) \mid \theta\right\}
$$

subject to

$$
\begin{aligned}
\int_{0}^{\mathrm{I}_{N}} p_{i}(S) c_{N, i} d i+c_{T}+b^{\prime}, & =(1+r) b+w(S) n+\pi_{N}(S)+\pi_{T}(S), \\
\mathrm{I}_{N} & =\Psi^{d}\left[Q^{g}(S)\right] d, \\
n^{\prime} & =(1-\lambda) n+\Phi^{w}\left[Q^{e}(S)\right](1-n), \\
S^{\prime} & =G(S) .
\end{aligned}
$$

This problem involves choosing how much to consume of each variety, $c_{N, i}$. Instead, we can solve a two-stage problem. In the first stage, we choose the number of varieties, the expenditures in nontradable consumption, and the expenditures in tradable consumption. In the second stage, we solve how much $c_{N . i}$ to purchase of each variety $i$ given the number of varieties $I_{N}$ and the total expenditure $Z$ of nontradable consumption. We can write the second stage as written as

$$
\max _{c_{i}}\left[\int_{0}^{\mathrm{I}_{N}} c_{i}^{\frac{1}{\rho}}\right]^{\rho},
$$

subject to

$$
\int_{0}^{\mathrm{I}_{N}} p_{i} c_{N, i} \leq Z
$$

The first order condition gives

$$
c_{N, i}=c_{N, j}\left(\frac{p_{i}}{p_{j}}\right)^{\frac{\rho}{1-\rho}}
$$


Define the consumption bundle $c_{N}$ and the price index $p$ as

$$
\begin{aligned}
c_{N} & =\left[\frac{1}{\mathrm{I}_{N}} \int_{0}^{\mathrm{I}_{N}} c_{N, i}^{\frac{1}{\rho}}\right]^{\rho}, \\
p & =\left[\frac{1}{\mathrm{I}_{N}} \int_{0}^{\mathrm{I}_{N}} p_{i}^{\frac{1}{1-\rho}}\right]^{1-\rho} .
\end{aligned}
$$

Substituting Equation (A.8) into the budget constraint gives

$$
c_{N . i}=\left(\frac{p_{i}}{p}\right)^{\frac{\rho}{1-\rho}} \frac{Z}{p \mathrm{I}_{N}}
$$

Combining Equation (A.11) and the definition of $c_{N}$ leads to

$$
\int_{0}^{\mathrm{I}_{N}} p_{i} c_{N, i}=p \mathrm{I}_{N} c_{N} .
$$

It is then straightforward to derive the demand schedule for each variety:

$$
c_{N, i}=\left(\frac{p_{i}}{p}\right)^{\frac{\rho}{1-\rho}} c_{N}^{\prime},
$$

and we only need to keep track of $c_{N}$ and $I_{N}$ in the utility function:

$$
\left[\int_{0}^{\mathrm{I}_{N}}{ }^{\frac{1}{\rho}}{ }_{N, i}^{\rho}\right]^{\rho}=c_{N} \mathrm{I}_{N}^{\rho} .
$$

Note that under the assumption that search in the goods market is undirected, the price index $p$ is independent of the number of varieties $I_{N}$. All the derivations above do not rely on the assumption that all prices for nontradables are equal, even though this is indeed the case in equilibrium. In the end, we can rewrite the household's problem as

$$
V(S, b, n)=\max _{c_{N}, c_{T}, I_{N}, d} u\left(c_{A}, d, n\right)+\beta \mathbb{E}\left\{V\left(S^{\prime}, b^{\prime}, n^{\prime}\right) \mid \theta\right\}
$$


subject to

$$
\begin{aligned}
c_{A} & =\left[\omega\left(c_{N} \mathrm{I}_{N}^{\rho}\right)^{-\eta}+(1-\omega) c_{T}^{-\eta}\right]^{-\frac{1}{\eta}} \\
p(S) c_{N} \mathrm{I}_{N}+c_{T}+b^{\prime} & =(1+r) b+w(S) n+\pi_{N}(S)+\pi_{T}(S), \\
\mathrm{I}_{N} & =\Psi^{d}\left[Q^{g}(S)\right] d \\
n^{\prime} & =(1-\lambda) n+\Phi^{w}\left[Q^{e}(S)\right](1-n), \\
S^{\prime} & =G(S) .
\end{aligned}
$$

\section{B Discussion of GHH Preferences}

We choose $\mathrm{GHH}$ preferences between consumption and the shopping disutility to allow the number of varieties of nontradable goods to be a normal good. Consider the following simplified static problem without tradable goods:

$$
\begin{aligned}
& \max _{c, \mathrm{I}, d} \frac{1}{1-\sigma}\left(c \mathrm{I}^{\rho}-d\right)^{1-\sigma} \\
& \text { subject to } \quad c \mathrm{I}=E \text {, } \\
& \mathrm{I}=d \Psi^{d}(Q),
\end{aligned}
$$

where $E$ is total income and the price is normalized to 1 . After substituting the constraints into the objective function and defining $A=\left(\Psi^{d}(Q)\right)^{-1}$, the original problem can be rewritten as

$$
\max _{\mathrm{I}} E \mathrm{I}^{\rho-1}-A \mathrm{I}
$$

The first order condition gives

$$
(\rho-1) E \mathrm{I}^{\rho-2}=A
$$

The solution of the problem is

$$
\mathrm{I}^{*}=E^{\frac{1}{2-\rho}}(\rho-1)^{\frac{1}{2-\rho}} A^{\frac{-1}{2-\rho}} .
$$

Note that $\mathrm{I}^{*}$ is increasing in $E$ if $2-\rho>0$. Since typical estimates of $\rho$ are between 1 and 1.5 , this condition is not restrictive. The number of varieties is a normal good. 


\section{Alternative Model Specifications}

Frictionless Economy The frictionless economy we considered is a two-sector small open economy without frictions in either the labor or the goods markets. Households still value varieties but do not need to search to find them. Therefore, $\mathrm{I}_{N}=1$ and the aggregated nontradable goods is $c_{N}=\left[\int_{0}^{1} c_{N, i}^{\frac{1}{\rho}} d i\right]^{\rho}$, with the price index defined as $p=\left[\int_{0}^{1} p_{i}^{\frac{1}{1-\rho}} d i\right]^{1-\rho}$. Households choose how much labor to supply, firms are able to immediately adjust labor input and the wage rate clears the market. We assume a standard additively separable utility function $u(c, n)=\frac{c^{1-\sigma}}{1-\sigma}-\xi_{n} \frac{n^{1+\gamma}}{1+\gamma}$. The problem of households is

$$
V(S, b)=\max _{c_{N}, c_{T}, n, b^{\prime}} u(c, n)+\beta \mathbb{E}\left\{V\left(S^{\prime}, b^{\prime}\right) \mid \theta\right\}
$$

subject to

$$
\begin{aligned}
& p(S) c_{N}+c_{T}+b^{\prime}=(1+r) b+w(S) n+\pi_{N}(S)+\pi_{T}(S) \\
& S^{\prime}=G(S)
\end{aligned}
$$

where $\left[\omega\left(c_{N}\right)^{\frac{\eta-1}{\eta}}+(1-\omega) c_{T}^{\frac{\eta-1}{\eta}}\right]^{\frac{\eta}{\eta-1}}$. Unlike in the baseline economy where $n$ evolves exogenously, here $n$ is a choice variable for households.

Firms in the nontradable goods sector solve the following problem:

$$
\begin{array}{ll}
\qquad \Omega^{N}(S, k)= & \max _{p_{i}, i, n} p_{i} C\left(p_{i}, S\right)-w(S) n-i+\mathbb{E}\left\{\frac{\Omega^{N}\left(S^{\prime}, k^{\prime}\right)}{1+r} \mid \theta\right\}, \\
\text { subject to } & C\left(p_{i}^{c}, S\right) \leq F^{N}(k, n), \\
& k^{\prime}=(1-\delta) k+i-\phi^{N}(k, i), \\
& S^{\prime}=G(S) .
\end{array}
$$

Firms in the tradable goods sector solve the following problem:

$$
\begin{array}{ll}
\Omega^{T}\left(S, k, n^{-}\right)= & \max _{i, n} F^{T}(k, n)-w(S) n_{T}-i_{T}-\phi^{T, n}\left(n, n^{-}\right)+\mathbb{E}\left\{\frac{\Omega^{T}\left(S^{\prime}, k^{\prime}, n\right)}{1+r} \mid \theta\right\}(C .8) \\
\text { subject to } & k^{\prime}=(1-\delta) k+i-\phi^{T, k}(k, i), \\
& S^{\prime}=G(S) .
\end{array}
$$


Frictionless Economy + Goods Market Friction This model economy has competitive labor markets and frictions in the goods markets; that is, households need to search for varieties, but they can choose how much to work. The period utility function for the household is $u(c, d, n)=$ $\frac{1}{1-\sigma}\left(c-\xi_{d} d\right)^{1-\sigma}-\xi_{n} \frac{n^{1+\gamma}}{1+\gamma}$. The problem of households is

$$
\begin{array}{ll}
\qquad V(S, b, n)= & \max _{c_{N}, c_{T}, \mathrm{I}_{N}, d} u(c, d, n)+\mathbb{E}\left\{\beta V\left(S^{\prime}, b^{\prime}, n^{\prime}\right) \mid \theta\right\} \\
& \\
\text { subject to } & p(S) c_{N} \mathrm{I}_{N}+c_{T}+b^{\prime}=(1+r) b+w(S) n+\pi_{N}(S)+\pi_{T}(S), \\
& \mathrm{I}_{N}=d \Psi^{d}\left[Q^{g}(S)\right] \\
& n^{\prime}=(1-\lambda) n+\Phi^{w}\left[Q^{e}(S)\right](1-n) \\
& S^{\prime}=G(S) .
\end{array}
$$

where $\left[\omega\left(c_{N} \mathrm{I}_{N}^{\rho}\right)^{\frac{\eta-1}{\eta}}+(1-\omega) c_{T}^{\frac{\eta-1}{\eta}}\right]^{\frac{\eta}{\eta-1}}$.

The problem of the firms in the nontradable goods sector is

$$
\begin{array}{ll}
\qquad \Omega^{N}(S, k)= & \max _{p_{i}, i, n} \Psi^{f}\left[Q^{g}(s)\right] p_{i} C\left(p_{i}, S\right)-w(S) n-i+\mathbb{E}\left\{\frac{\Omega^{N}\left(S^{\prime}, k^{\prime}\right)}{1+r} \mid \theta\right\}, \\
\text { subject to } & C\left(p_{i}^{c}, S\right) \leq F^{N}(k, n), \\
& k^{\prime}=(1-\delta) k+i-\phi^{N}(k, i), \\
& S^{\prime}=G(S) .
\end{array}
$$

The problem of the firms in the tradable goods sector is the same as in the frictionless economy.

Baseline Economy - Goods Market Friction The third alternative model economy that we consider has frictions in the labor market but not in the goods markets. Households cannot choose their labor. The period utility function for the household is $u(c, n)=\frac{c^{1-\sigma}}{1-\sigma}-\varsigma n$. Here, the consumers have neither a shopping choice, nor a labor choice (no need to shop, and they work as 
much as they can). The problem of the household is

$$
V(S, b, n)=\max _{c_{N}, c_{T}, b} u(c, n)+\mathbb{E}\left\{\beta V\left(S^{\prime}, b^{\prime}, n^{\prime}\right) \mid \theta\right\}
$$

subject to

$$
\begin{aligned}
& p(S) c_{N}+c_{T}+b^{\prime}=(1+r) b+w(S) n+\pi_{N}(S)+\pi_{T}(S) \\
& n^{\prime}=(1-\lambda) n+\Phi^{w}\left[Q^{e}(S)\right](1-n) \\
& S^{\prime}=G(S)
\end{aligned}
$$

where $\left[\omega\left(c_{N}\right)^{\frac{\eta-1}{\eta}}+(1-\omega) c_{T}^{\frac{\eta-1}{\eta}}\right]^{\frac{\eta}{\eta-1}}$. While the problem of the firms in the tradable goods sector is the same as in the baseline economy, firms in the nontradable goods sector solve

$$
\Omega^{N}(S, k, n)=\max _{p_{i}, i, v} p_{i} C\left(p_{i}, S\right)-w(S) n-i-v \kappa+\mathbb{E}\left\{\frac{\Omega^{N}\left(S^{\prime}, k^{\prime}, n^{\prime}\right)}{1+r} \mid \theta\right\}
$$

subject to

$$
\begin{aligned}
& C\left(p_{i}^{c}, S\right) \leq F^{N}(k, n) \\
& k^{\prime}=(1-\delta) k+i-\phi^{N}(k, i), \\
& n^{\prime}=(1-\lambda) n+\Phi^{f}\left[Q^{e}(S)\right] v, \\
& S^{\prime}=G(S) .
\end{aligned}
$$




\section{Calibration of Alternative Model Economies}

TABlE 8

Exogenously Determined Parameters in the Frictionless Economy

\begin{tabular}{lc}
\hline \hline \multicolumn{1}{c}{ Parameter } & Value \\
\hline Risk aversion, $\sigma$ & 2.0 \\
Annual rate of return, $\beta$ & $\frac{1}{\beta^{8}}-1=4 \%$ \\
Elasticity of substitution bw tradables and nontradables, $\eta$ & 0.83 \\
Working Frisch elasticity, $\gamma$ & 1.50 \\
Price markup $\rho$ & 1.05 \\
\hline \hline
\end{tabular}

TABLE 9

Steady-State Targets and Associated Parameters in the Frictionless Economy

\begin{tabular}{lccc}
\hline \hline Target & Value & Parameter & Value \\
\hline Share of tradables $\frac{F_{T}^{*}}{Y^{*}}$ & 0.3 & $\omega$ & 0.90 \\
Fraction of time working, $n^{*}$ & 0.3 & $\xi_{n}$ & 26.66 \\
Capital to output ratio $\frac{K^{*}}{Y^{*}}$ & 2.75 & $\delta$ & 0.009 \\
Labor share in nontradables & 0.6 & $\theta_{N}$ & 0.63 \\
Labor share in tradables & 0.6 & $\theta_{T}^{N}$ & 0.60 \\
Equal role of capital and land in tradables, & $2 \theta_{T}^{K}+\theta_{T}^{N}=1$ & $\theta_{T}^{K}$ & 0.20 \\
\hline & Units Parameters & & \\
\hline Output, $Y^{*}$ & 1 & $z_{N}$ & 0.64 \\
Relative price of nontradables, $p^{*}$ & 1 & $z_{T}$ & 0.95 \\
\hline \hline
\end{tabular}


TABLE 10

Exogenously Determined Parameters

in the Economy with Goods Frictions but without Labor Frictions

\begin{tabular}{lc}
\hline \hline \multicolumn{1}{c}{ Parameter } & Value \\
\hline Risk aversion, $\sigma$ & 2.0 \\
Annual rate of return, $\beta$ & $\frac{1}{\beta^{8}}-1=4 \%$ \\
Elasticity of substitution bw tradables and nontradables, $\eta$ & 0.83 \\
Working Frisch elasticity, $\gamma$ & 1.50 \\
Price markup $\rho$ & 1.05 \\
\hline \hline
\end{tabular}

TABLE 11

Steady-State Targets and Associated Parameters

in the Economy with Goods Frictions but without Labor Frictions

\begin{tabular}{lccc}
\hline \hline Target & Value & Parameter & Value \\
\hline Share of tradables $\frac{F_{T}^{*}}{Y^{*}}$ & 0.3 & $\omega$ & 0.91 \\
Fraction of time working, $n^{*}$ & 0.3 & $\xi_{n}$ & 27.89 \\
Occupancy rate, $\frac{C_{N}^{*}}{F_{N}^{*}}$ & .81 & $\nu^{g}$ & 0.81 \\
Capital to output ratio $\frac{K^{*}}{Y^{*}}$ & 2.75 & $\delta$ & 0.009 \\
Labor share in nontradables & 0.6 & $\theta_{N}$ & 0.63 \\
Labor share in tradables & 0.6 & $\theta_{T}^{N}$ & 0.60 \\
Equal role of capital and land in tradables, & $2 \theta_{T}^{K}+\theta_{T}^{N}=1$ & $\theta_{T}^{K}$ & 0.20 \\
\hline \multicolumn{1}{c}{ Units Parameters } & & \\
\hline Output, $Y^{*}$ & 1 & $z_{N}$ & 0.80 \\
Relative price of nontradables, $p^{*}$ & 1 & $z_{T}$ & 0.95 \\
Market tightness in goods markets, $D^{*}$ & 1 & $\xi_{d}$ & 0.02 \\
\hline \hline
\end{tabular}


TABLE 12

Exogenously Determined Parameters

in the Economy with Labor Frictions but without Goods Markets Frictions

\begin{tabular}{lc}
\hline \hline \multicolumn{1}{c}{ Parameter } & Value \\
\hline Risk aversion, $\sigma$ & 2.0 \\
Annual rate of return, $\beta$ & $\frac{1}{\beta^{8}}-1=4 \%$ \\
Labor matching elasticity, $\mu$ & 0.50 \\
Elasticity of substitution bw tradables and nontradables, $\eta$ & 0.83 \\
Workers' bargaining power, $\varphi$ & 0.35 \\
Price markup $\rho$ & 1.05 \\
\hline \hline
\end{tabular}

TABLE 13

Steady-State Targets and Associated Parameters

in the Economy with Labor Frictions but without Goods Markets Frictions

\begin{tabular}{lccc}
\hline \hline Target & Value & Parameter & Value \\
\hline Share of tradables $\frac{F_{T}^{*}}{Y^{*}}$ & 0.3 & $\omega$ & 0.91 \\
Unemployment rate, $U^{*}$ & $7 \%$ & $\lambda$ & 0.05 \\
Monthly job finding rate & $45 \%$ & $\nu^{e}$ & 0.67 \\
Capital to output ratio $\frac{K^{*}}{Y^{*}}$ & 2.75 & $\delta$ & 0.007 \\
Labor share in nontradables & 0.6 & $\theta_{N}$ & 0.67 \\
Labor share in tradables & 0.6 & $\theta_{T}^{N}$ & 0.64 \\
Equal role of capital and land in tradables, & $2 \theta_{T}^{K}+\theta_{T}^{N}=1$ & $\theta_{T}^{K}$ & 0.18 \\
Vacancy posting to output ratio & 0.037 & $\varsigma$ & 0.73 \\
\hline \multicolumn{2}{c}{ Units Parameters } & & \\
\hline Output, $Y^{*}$ & 1 & $z_{N}$ & 0.36 \\
Relative price of nontradables, $p^{*}$ & 1 & $\kappa$ & 0.52 \\
Market tightness in labor markets, $\frac{U^{*}}{V^{*}}$ & 1 & & 0.53 \\
\hline
\end{tabular}




\section{E Calibration of Models with Financial Frictions}

The exogenously determined parameters are the same as for the baseline economy, and we do not report them here.

TABLE 14

Steady-State Targets and Associated Parameters

in the Financial Shocks Economy with Nonsegmented Goods Markets (I)

\begin{tabular}{lccc}
\hline \hline Target & Value & Parameter & Value \\
\hline Share of tradables $\frac{F_{T}^{*}}{Y^{*}}$ & 0.3 & $\omega$ & 0.91 \\
Unemployment rate, $U^{*}$ & $7 \%$ & $\lambda$ & 0.05 \\
Monthly job finding rate & $45 \%$ & $\nu^{e}$ & 0.67 \\
Occupancy rate, $\frac{C_{N}^{*}}{F_{N}^{*}}$ & 0.81 & $\nu^{g}$ & 0.81 \\
Capital to output ratio $\frac{K^{*}}{Y^{*}}$ & 2.75 & $\delta$ & 0.007 \\
Labor share in tradables & 0.6 & $\theta_{T}^{N}$ & 0.64 \\
Equal role of capital and land in tradables, & $2 \theta_{T}^{K}+\theta_{T}^{N}=1$ & $\theta_{T}^{K}$ & 0.18 \\
Vacancy posting to output ratio & 0.037 & $\theta_{N}$ & 0.67 \\
Financial cost to output ratio & 0.01 & $\psi$ & 0.28 \\
\hline & \multicolumn{1}{c}{ Units Parameters } & & \\
\hline Output, $Y^{*}$ & 1 & $z_{N}$ & 0.45 \\
Relative price of nontradables, $p^{*}$ & 1 & $\kappa$ & 0.52 \\
Market tightness in labor markets, $\frac{U^{*}}{V^{*}}$ & 1 & $\xi$ & 0.53 \\
Market tightness in goods markets, $D^{*}$ & 1 & & 0.02 \\
\hline
\end{tabular}


TABLE 15

Steady-State Targets and Associated Parameters in the Financial Shocks Economy with Nonsegmented Goods Markets (II)

\begin{tabular}{lccc}
\hline \hline Target & Value & Parameter & Value \\
\hline Share of tradables $\frac{F_{T}^{*}}{Y^{*}}$ & 0.3 & $\omega$ & 0.91 \\
Unemployment rate, $U^{*}$ & $7 \%$ & $\lambda$ & 0.05 \\
Monthly job finding rate & $45 \%$ & $\nu^{e}$ & 0.67 \\
Occupancy rate, $\frac{C_{N}^{*}}{F_{N}^{*}}$ & 0.81 & $\nu^{g}$ & 0.81 \\
Capital to output ratio $\frac{K^{*}}{Y^{*}}$ & 2.75 & $\delta$ & 0.007 \\
Labor share in tradables & 0.6 & $\theta_{T}^{N}$ & 0.64 \\
Equal role of capital and land in tradables, & $2 \theta_{T}^{K}+\theta_{T}^{N}=1$ & $\theta_{T}^{K}$ & 0.18 \\
Vacancy posting to output ratio & 0.037 & $\theta_{N}$ & 0.67 \\
Financial cost to output ratio & 0.01 & $\psi$ & 0.28 \\
\hline \multicolumn{2}{c}{ Units Parameters } & & \\
\hline Output, $Y^{*}$ & 1 & $z_{N}$ & 0.45 \\
Relative price of nontradables, $p^{*}$ & 1 & $z_{T}$ & 0.52 \\
Market tightness in labor markets, $\frac{U^{*}}{V^{*}}$ & 1 & $\kappa$ & 0.53 \\
Market tightness in goods markets, $D^{*}$ & 1 & $\xi$ & 0.02 \\
\hline
\end{tabular}


FIGURE 7

Impulse Responses in the Baseline Economy and in the Economies without Labor Market Frictions

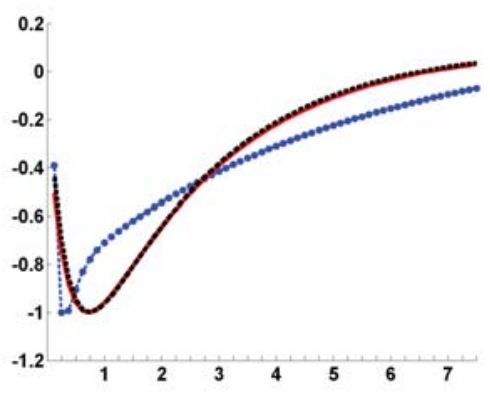

Real output

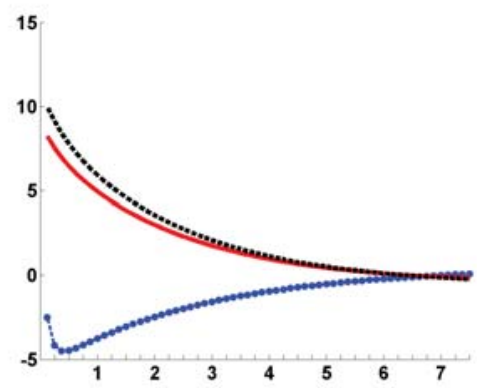

Consumption

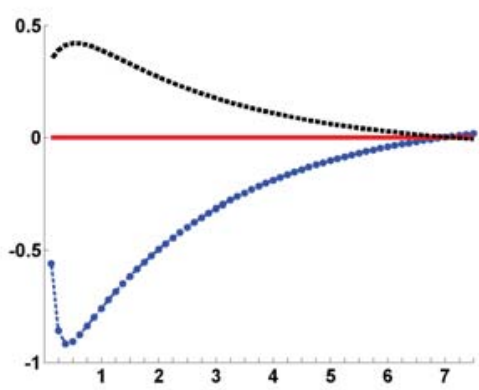

Number of varieties

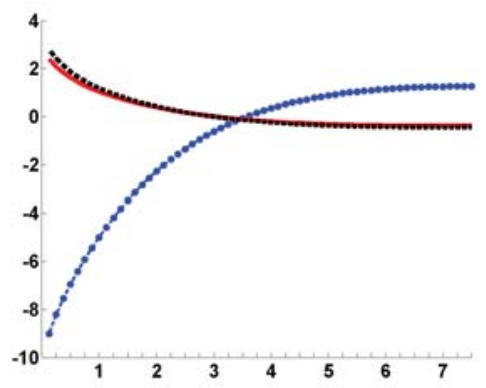

Investment

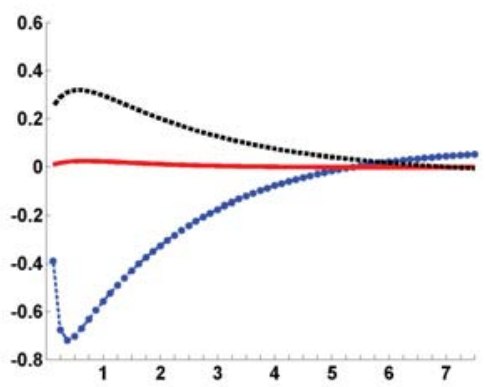

Solow residual

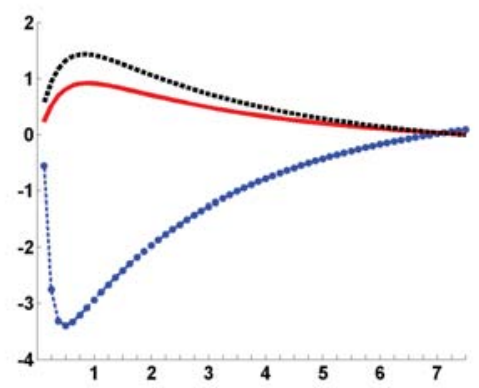

Output of nontradable

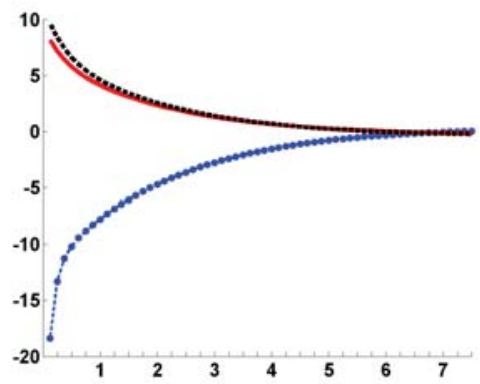

Price for nontradable

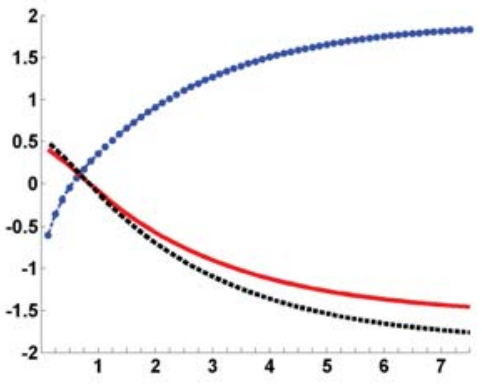

Wealth 56

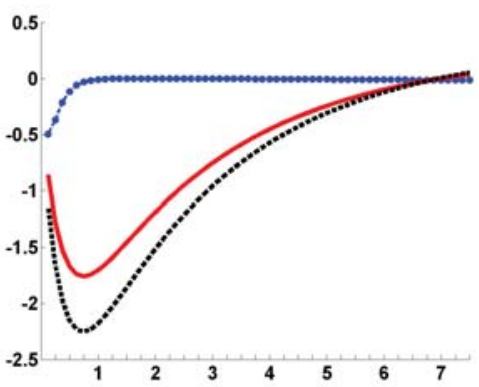

Employment

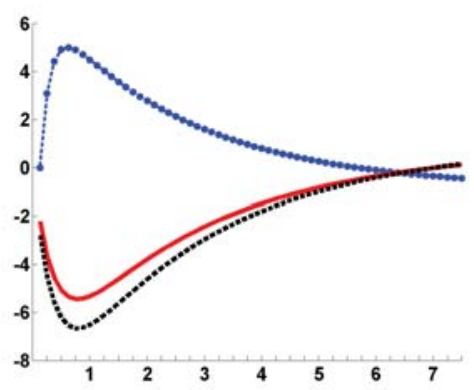

Output of tradable

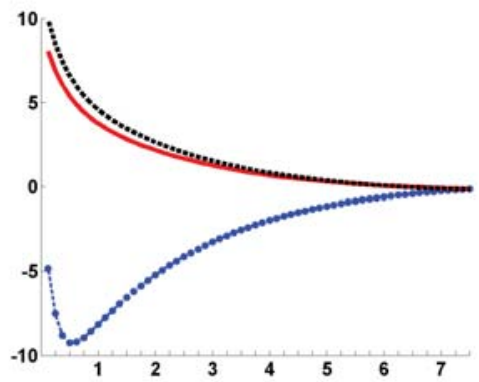

Wage

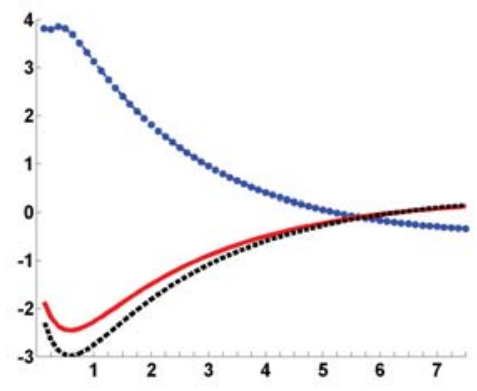

Net export/output ratio

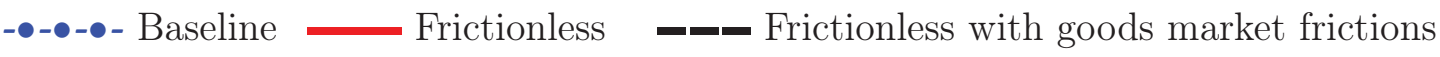

